ELOIZA DE REZENDE

\title{
ESTUDO DA EXPRESSÃO DE ARKADIA, PROTEÍNA E3 DE UBIQUITINAÇÃO, EM TUMORES DE TIRÓIDE E SUA RELAÇÃO COM A VIA DE SINALIZAÇÃO DE TGF-BETA
}

Dissertação apresentada ao Instituto de Ciências Biomédicas da Universidade de São Paulo, para obtenção do Título de Mestre em Ciências (Biologia Celular e Tecidual).

São Paulo

2009 
ELOIZA DE REZENDE

\title{
ESTUDO DA EXPRESSÃO DE ARKADIA,
}

\author{
PROTEÍNA E3 DE UBIQUITINAÇÃO, EM
}

TUMORES DE TIRÓIDE E SUA RELAÇÃO COM A

VIA DE SINALIZAÇÃO DE TGF-BETA

Dissertação apresentada ao

Instituto de Ciências Biomédicas da

Universidade de São Paulo, para

obtenção do Título de Mestre em

Ciências.

Área de concentração:

Biologia Celular e Tecidual

Orientadora:

Profa. Dra. Edna Teruko

Kimura

São Paulo

2009 
DADOS DE CATALOGAÇÃO NA PUBLICAÇÃO (CIP)

Serviço de Biblioteca e Informação Biomédica do

Instituto de Ciências Biomédicas da Universidade de São Paulo

(C) reprodução total

\section{Rezende, Eloiza.}

Estudo da expressão de Arkadia, proteína E3 de ubiquitinação, em tumores de tiróide e sua relação com a via de sinalização de TGFbeta / Eloiza Rezende. -- São Paulo, 2009.

Orientador: Edna Teruko Kimura.

Dissertação (Mestrado) - Universidade de São Paulo. Instituto de Ciências Biomédicas. Departamento de Biologia Celular e do Desenvolvimento. Área de concentração: Biologia Celular e Tecidual. Linha de pesquisa: Biologia molecular da glândula Tiróide.

Versão do título para o inglês: Study of Arkadia expression , ubiquitination E-3 protein, in thyroid tumors and its relation to the TGFbeta signaling pathway.

Descritores: 1. Arkadia 2. E3 ubiquitina ligase 3. TGF-beta 4. Ubiquitinação 5. Carcinoma anaplásico de tiróide 6. ARO I. Kimura, Edna Teruko II. Universidade de São Paulo. Instittuto de Ciências Biomédicas. Programa de Pós Graduação em Biologia Celular e Tecidual III. Título. 
Título da Dissertação: $\quad$ Estudo da expressão de Arkadia, proteína E3 de ubiquitinação, em tumores de tiróide e sua relação com a via de sinalização de TGF-beta .

Orientador(a): $\quad$ Edna Teruko Kimura.

A Comissão Julgadora dos trabalhos de Defesa da Dissertação de Mestrado, em sessão pública realizada a .................................,
( ) Aprovado(a)
( ) Reprovado(a)

Examinador(a): Assinatura:

Nome:

Instituição:

Examinador(a): Assinatura:

Nome:

Instituição:

Presidente: Assinatura:

Nome:

Instituição: 
Aos meus pais, Luiz e Verginia, meus irmãos, Mônica e Leonardo e sobrinhos, Felipe e Thales, pelo amor incondicional e por me ensinarem a ser uma pessoa melhor a cada dia. 


\section{AGRADECIMENTOS}

Aos meus pais, Luiz e Verginia, pelo carinho, confiança, incentivo, amor e por apoiarem todas minhas decisões; em especial à minha mãe pela cumplicidade, companheirismo, ajuda (em todos os sentidos) e principalmente por me ensinar a ter caráter, ser uma pessoa melhor a cada dia e por ser meu portoseguro, amo muito vocês.

Aos meus irmãos, Mônica, Leonardo e Paula, que sempre me incentivaram, deram o apoio do qual precisei, por tornarem minha família mais completa e por realizarem um de meus sonhos.... virar tia!!! Aos sobrinhos, Felipe e Thales por alegrarem cada dia mais minha vida.

Às minhas avós, pelo carinho e atenção; aos tios Carlos, Rogério, Mônica, Maurício, Lia, Regina, Paulo, Jorge, Fátima e Vera pelo exemplo de luta, coragem, carinho e incentivo, em especial ao Carlos, por toda ajuda e exemplo de generosidade e à Regina (minha segunda mãe). Aos primos, Douglas, Denise, Luciana, Alessandra, Claúdia, Tiago, Rodrigo, Henrique, Gabriel e Natália por todas as piadas compartilhadas e por também fazerem parte desta história e em especial à prima Nádhia, que mesmo distante me deu carinho, conselhos, ajuda e sempre torceu pelo meu sucesso e felicidade.... Amo muito todos vocês.....

Aos colegas e amigos de laboratório, Sílvia pela competência, Fabiana por sua serenidade, Simone por todas as visitas inesperadas, Suzana por ser um exemplo de vida e pelos conselhos valiosos, Luciane por tudo que me ensinou (calma Lu, eu já era desastrada), Júlio pela força, pelas rimas e funks, Ana pelo carinho que superou as brigas, Marley pela ternura, César por me apresentar ao "bandejão" e sempre ouvir meus desabafos, Murilo pelas histórias e discussões (inclusive sobre futebol), Kellen pelo companheirismo, conselhos e por me emprestar seu ouvido, Alex por ser a pessoa mais estranha que conheço (e que adoro por isso), Gabriela pelo bom-humor 
matinal e Sabrina pela alegria e cantorias, agradeço à todos o apoio, amizade e experiências de vida e de trabalho que compartilhamos.

Aos amigos de longa data Renata Santiago, Artur Pereira e Giovana Lacanna, pelos ombros e ouvidos emprestados nos momentos necessários, pelo incentivo, pelas palavras de carinho e horas de descontração ou pelo fato de existirem em minha vida.

Aos amigos que fiz no ICB que estarão em meu coração para sempre e sem os quais meus dias no departamento não teriam sido tão especiais - Tati(lene), Vivian, Nathasha, Juliano, Lu Capelo, Uchida, Hélio, Fernanda, Paty, Lu Harumi, Ariane, Vanessa, Evandro, Juliana, Carla, Celiana e Ana.

Aos companheiros da raia, pela medalha de ouro e por todas as horas da madrugada (!!!) de concentração que na verdade eram horas de "des"concentração (do estresse diário).

Aos professores, alunos e funcionários do departamento e do ICB, pela amizade e ajuda.

Ao Dr J.A. Fagin e a Dra. Alison pela doação das linhagens celulares.

À Fundação de Amparo à Pesquisa do Estado de São Paulo (FAPESP), pelo apoio financeiro (Processo FAPESP: 06/53797-0), fundamental para a realização deste projeto.

Agradecimento especial à minha orientadora Edna, pela oportunidade de trabalhar em seu laboratório, pela paciência, conselhos, e conhecimento compartilhado, pela dedicação depositada durante toda a fase deste mestrado e por ser a responsável pela realização de um grande sonho.

Muito obrigada!!! 
"'Ostra feliz não faz pérola.'A ostra, para fazer uma pérola, precisa ter dentro de si um grão de areia que a faz sofrer. Sofrendo, a ostra diz para si mesma: 'Preciso envolver essa areia pontuda que me machuca com uma esfera lisa que Ihe tire as pontas...' Ostras felizes não fazem pérolas... Pessoas felizes não sentem a necessidade de criar. $O$ ato criador, seja na ciência ou na arte, surge sempre de uma dor. Não é preciso que seja uma dor doída... Por vezes a dor aparece como aquela coceira que tem o nome de curiosidade" 


\section{RESUMO}

REZENDE, E. Estudo da expressão de Arkadia, proteína E3 de ubiquitinação, em tumores de tiróide e sua relação com a via de sinalização de TGF-beta. 2009. 71 f. Dissertação (Mestrado em Biologia Celular e Tecidual) - Instituto de Ciências Biomédicas, Universidade de São Paulo, São Paulo, 2009.

Arkadia é uma proteína E-3 ubiquitina ligase que participa do processo de proteólise, pela via de ubiquitinação. Arkadia é conhecida por promover a amplificação da sinalização de TGF-beta, uma vez que reconhece especificamente SMAD7, levando a sua degradação, pelo proteassomo $26 \mathrm{~S}$. SMAD7 atua inibindo a sinalização de TGF-beta mediada por Smads. As Smads são responsáveis pelo reconhecimento do sinal gerado pelos receptores de TGF-beta e pela transcrição de genes específicos que levarão a inibição da proliferação em células epiteliais. Este estudo teve como objetivo caracterizar e investigar a influência de Arkadia em linhagens celulares de cânceres de tiróide. A expressão gênica de Arkadia em linhagens celulares de carcinomas papílifero (NPA), folicular (WRO) e anaplásico (ARO), foi avaliada por PCR quantitativo. Em ARO, cuja expressão de Arkadia foi maior que os outros tipos celulares, foram identificados dois subclones (ARO_1 e ARO_2) com diferentes níveis de expressão gênica de Arkadia, sendo ARO_2 > ARO_1. Da mesma maneira observamos que SMAD2, SMAD3, SMAD4 e SMAD7, estão mais expressos em ARO_2. A expressão protéica avaliada por Western blotting mostra que Arkadia está mais expressa em ARO_2. Comparando os subclones ARO_1 e ARO_2, observamos que a proliferação celular, realizada por contagem de células em câmara de Newbauer não apresenta diferenças significativas entre os dois subclones, enquanto a viabilidade (analisada por MTT) é a mesma nos dois subclones. No entanto o crescimento in vivo, realizado por ensaio de xenotransplante, mostra que o subclone ARO_2, com maior expressão de Arkadia, desenvolve um tumor de menor volume. Interessante notar que o subclone ARO_2 apresenta maior expressão de genes do ciclo celular modulados por TGF-beta (sendo MCM6 46,99\%, MAD2 42,58\% e CKS2 76,78\% > ARO_2 em relação a ARO_1). Os subclones de ARO respondem ao tratamento com peptídeo de TGF-beta1 e activina $A$, alterando 
a expressão dos genes MCM6, MAD2, CKS2, C-MYC, ARKADIA, SMAD7 e TGF$\beta$. Recentemente a identidade da linhagem ARO foi questionada, pois análises citogenéticas mostraram uma alta similaridade de ARO com a linhagem HT29, de carcinoma de cólon humano. Para comprovar a identidade de ARO as duas linhagens foram tratadas com butirato de sódio ( $\mathrm{NaBt}$ ), que reconhecidamente modifica as características morfológicas de HT29. No quarto dia de tratamento foi possível observar modificações em HT29, que em ARO não se observou durante 24 dias de tratamento. A expressão gênica de Arkadia é 495,36\% maior em ARO em comparação com HT29, assim como nos genes específicos da tiróide, PAX8 e TTF-1, indicando origens distintas de ARO e HT29. O fenômeno da expressão diferenciada de Arkadia, observado em subclone de ARO indica que esta enzima componente da via proteolítica está envolvida na modulação inibitória gerada pela via de sinalização de TGF-beta.

Palavras-chave: Arkadia; E-3 ubiquitina ligase; TGF-beta; Ubiquitinação; Carcinoma anaplásico de tiróide; ARO. 


\section{ABSTRACT}

REZENDE, E. Study of Arkadia expression, ubiquitination E-3 protein, in thyroid tumors and its relation to the TGF-beta signaling pathway. 2009. $71 \mathrm{f}$. Dissertação (Mestrado em Biologia Celular e Tecidual) - Instituto de Ciências Biomédicas, Universidade de São Paulo, São Paulo, 2009.

Arkadia is an E-3 ubiquitin ligase protein that participates in the process of proteolysi, by ubiquitination. Arkadia is known to promote amplification of the TGF-beta signaling, as specifically recognizes SMAD7, leading to its degradation by proteasome 26S. SMAD7 acts by inhibiting the TGF-beta signaling mediated by Smads. The Smads are responsible for recognition of the signal generated by the receptors of TGF-beta and the transcription of specific genes that lead to inhibition of proliferation in epithelial cells. This study aimed to characterize and investigate the influence of Arkadia in thyroid cancer cell lines of. The Arkadia gene expression in the papillary (NPA), follicular (WRO) and anaplastic (ARO) carcinoma cell lines, was evaluated by quantitative PCR. In ARO, the Arkadia expression was higher than other cell types, and subsequently two subclones with different levels of Arkadia were identified (ARO_1 and ARO_2) the being gene expression in ARO_2 > ARO_1. Similarly we observed that SMAD2, SMAD3, SMAD4 and SMAD7 were more expressed in ARO_2. The protein expression evaluated by Western blotting showed that Arkadia was more expressed in ARO_2. Comparing the ARO_1 and ARO_2 subclones, we observed by cell counting in Newbauer's chamber that cell proliferation showed no significant differences between the two subclones, and also the cell viability (assessed by MTT) which was similar in the two subclones. However, the in vivo growth, evaluated by xenotransplant, showed that the ARO_2 subclone, with higher Arkadia expression, developed tumors of lower volume. It is interesting to observe that ARO_2 subclone showed increased expression of the cell cycle genes modulated by TGF-beta (MCM6 is 46,99\%, MAD2 42,58\% and CKS2 76,78\% > ARO_2 for ARO_1). However the ARO subclones responded to treatment with TGF-beta1 and activin $A$ peptide altering the expression of MCM6, MAD2, CKS2, C-MYC, ARKADIA, SMAD7 and TGF- $\beta$ genes. Recently the identity of ARO cells was questioned because a cytogenetic analysis showed a high similarity between 
ARO and the cell line HT29, derived from human colon carcinoma. To prove the ARO identity both cell lines were treated with sodium butyrate (NaBt), recognized to induce morphological changes in HT29. On the fourth day of treatment, it was already possible to observe HT29 morphological changes, which in ARO were not observed during 24 days of treatment. The Arkadia gene expression is $495.36 \%$ higher in ARO compared with HT29, as well as the expression of thyroid specific genes, PAX8 and TTF-1, indicating distinct origins of HT29 and ARO. The phenomenon of differential expression of Arkadia observed in the ARO subclones indicates that this enzyme component of the proteolytic pathway is involved in the modulation of the inhibitory signal generated by the TGF-beta pathway.

Keywords: Arkadia; E-3 ubiquitin ligase; TGF-beta; Ubiquitination; Thyroid anaplastic carcinoma; ARO. 


\section{LISTA DE ILUSTRAÇÕES}

Figura 1. Esquema da sinalização celular de TGF-beta e activina 22

Figura 2. Esquema da proteólise pela via de ubiquitinação 24

Figura 3. Interação das E3 na via de ubiquitinação 25

Figura 4. Expressão gênica de Arkadia em linhagens celulares de carcinomas de tiróide 44

Figura 5. Expressão de Arkadia em linhagem celular de carcinoma anaplásico de tiróide 45

Figura 6. Expressão gênica de linhagem celular de carcinoma anaplásico de tiróide por PCR quantitativo para genes da via de sinalização TGF- $\beta /$ Activina 46

Figura 7. Ensaios de proliferação in vitro em linhagem celular de carcinoma anaplásico de tiróide

Figura 8. Crescimento tumoral da linhagem de carcinoma anaplásico de tiróide em camundongos atímicos

Figura 9. Expressão gênica de linhagem celular de carcinoma anaplásico de tiróide por PCR quantitativo para genes envolvidos com o ciclo celular 49

Figura 10. Expressão gênica de linhagem celular de carcinoma anaplásico de tiróide tratada com TGF- $\beta 1$, por PCR quantitativo 50

Figura 11. Expressão gênica de linhagem celular de carcinoma anaplásico de tiróide tratada com activina A, por PCR quantitativo_

Figura 12. Expressão gênica de Arkadia em linhagem celular ARO e HT29, por PCR quantitativo

Figura 13. Expressão de genes de diferenciação tiroidiana nas linhagens ARO e HT29, por PCR quantitativo 53

Figura 14. Linhagens ARO e HT29 tratadas com butirato de sódio 54

Figura 15. Linhagens ARO e HT29 tratadas com butirato de sódio após a primeira passagem 
Figura 16. Linhagens ARO e HT29 após tratamento com butirato de sódio 


\section{LISTA DE TABELAS}

Tabela 1. Smads recrutados por membros da superfamília TGF-beta 19

Tabela 2. Tipos de E3 da via de sinalização de TGF-beta 26

Tabela 3. Comparação entre a sequência de aminoácidos de Arkadia em vertebrados 27

Tabela 4. Lista de primers utilizados para RT-PCR quantitativo 38

Tabela 5. Gradação da positividade dos tecidos submetidos ao ensaio imuno-histoquímico para a proteína ARKADIA 43 


\section{LISTA DE ABREVIATURAS}

ActR- receptor de activina ATP - Adenosina tri-fofosfato

BMP-bone morphogenic protein cDNA - DNA complementar CDK- kinase dependente de ciclina CHIP - Carboxil terminus of Hsp70 interacting protein CKS2- CDC28 protein kinase 2

Co-Smad - common mediator Smad CSC - Cancer stem cell

$\mathrm{CT}$ - threshold cycle

DMEM - Dulbecco's Modified Eagle's Medium

dNTP - deoxinucleotídeo trifosfatado

DP- desvio padrão

E1 - Enzima ativadora de ubiquitina

E2 - Enzima conjugadora de enzima

E3 - Enazima ubiquitina ligase

ECACC - European Collection of Cell cultures

ERK - Extracellular signal-Regulated Kinases

FWD - Forward

GDF- growth and differentiation factor

GDNF- glial-derived neurotropic growth factor

$\mathrm{HCl}$ - Ácido Clorídrico

HETC - Homologous to the E6-AP carboxyl terminus

I-Smad - Smad Inibitório

JNK/SAPK - c-Jun N-terminal Kinases/stress-activated protein kinase MAD2L1- MAD2 mitotic arrest deficient-like 1 
MAPK - mitogen-activated protein kinase

MCM6 - minichromosome maintenance deficient (mis5, S. pombe) 6

MIS - müllerian - inhibiting substance

MTT- 3-(4,5-dimethylthiazolyl-2)-2,5-diphenyltetrazolium bromide

NaBt - Butirato de sódio

NLS - Nuclear localization signal

$\mathrm{pb}$ - pares de bases

$P C R$ - reação em cadeia por polimerase

REV - Reverse

R-Smad - receptor regulated Smad

RNase - ribonuclease

RNAi - RNA de interferência

RNF111 - Ring-finger 111

RPL19 - proteína ribossomal L19

RPMI - Roswell Park Memorial Institute medium

RT - transcrição reversa

SBF - soro bovino fetal

Smurf - Smad ubiquitination regulatory factor

SnoN - Ski-related novel protein $\mathrm{N}$

$\mathrm{SP}$ - Side population

TGF $\beta$ - fator de crescimento transformador beta

TPC-1- linhagem celular de carcinoma papilífero de tiróide humana

$\mathrm{T} \beta \mathrm{R}$ - receptor de TGF $\beta$

Ub - ubiquitina 


\section{SUMÁRIO}

1 INTRODUÇÃO 18

1.1 TGF-beta e Sinalização Smad 19

1.2 Proteólise pela Via de Ubiquitinação 23

1.3 Arkadia 26

1.4 Sinalização TGF-beta e Câncer 28

2 OBJETIVO 31

3 MATERIAIS E MÉTODOS 32

3.1 Tecido de tiróide humana 32

3.1.1 Processamento dos tecidos para corte histológico 32

3.1.1.1 Coloração para hematoxilina e eosina 33

3.1.1.2 Expressão protéica de Arkadia nos tecidos tireoidianos humanos. 33

3.1.1.2.1 Imuno-histoquímica 33

3.2 Cultura Celular 34

3.3 Proliferação Celular 35

3.3.1 Contagem do Número de Células 35

3.4 Viabilidade Celular 35

3.4.1 Ensaio de 3-(4,5-dimethylthiazolyl-2)-2,5-diphenyltetrazolium bromide - MTT 35

3.5 Análise da Expressão Gênica 36

3.5.1 PCR quantitativo Real Time 36

3.5.1.1 Extração de RNA Total 36

3.5.1.2 Transcrição Reversa (RT) 36

3.5.1.3 PCR quantitativo Real Time 37

3.6 Análise da Expressão Proteica 39

3.6.1 Western blotting 39

3.7 Tratamento com proteínas recombinantes de activina A e de TGF $\beta 1$ 40

3.8 Xenotransplante 41 
3.9 Tratamento com butirato de sódio 41

3.10 Análise estatística 42

4 RESULTADOS 43

4.1 Expressão de Arkadia tecidos de tiróide 43

4.2 Expressão Gênica de Arkadia em Linhagens Celulares de Câncer de Tiróide 43

4.3 Expressão de Arkadia em sub-clones de linhagem celular de carcinoma anaplásico de tiróide 44

4.4 Expressão gênica de membros da sinalização Smads nos clones ARO 1 e ARO2 46

4.5 Proliferação in vitro dos clones ARO 1 e ARO 2 46

4.6 Proliferação in vivo dos clones ARO 1 e ARO 2

4.7 Expressão de genes envolvidos com o ciclo celular nos clones ARO 1 e ARO 2 48

4.8 Tratamento de ARO 1 e ARO 2 com TGF- $\beta 1$ e activina A 49

4.9 Caracterização da linhagem celular de carcinoma anaplásico de tiróide - ARO 51

4.9.1 Expressão gênica de Arkadia 51

4.9.2 Expressão gênica de $P A X-8$ e TTF-1 52

4.9.3 Diferenciação com butirato de sódio 53

5 DISCUSSÃO 57

6 CONCLUSÕES 64

REFERÊNCIAS 65 


\section{INTRODUÇÃO}

TGF-beta (transforming growth factor-beta) e activina são fatores de crescimento que fazem parte da grande família dos TGFbetas, entre outras características apresentam em comum a mesma via de sinalização, a via dos Smads. Após o reconhecimento do fator de crescimento por um receptor de membrana específico, as proteínas CoSmads são ativadas e formarão um complexo com uma R-Smad que em conjunto serão translocados para o núcleo onde ativarão genes alvos. Essa via pode sofrer a influencia de um Smad inibitório, I-Smad, que impedirá a formação do complexo, inibindo a via de sinalização (MASSAGUE e WOTTON, 2000; PANGAS e WOODRUFF, 2000). As Smads podem sofrer também a influência da via de ubiquitinação, responsável pela proteólise celular, inibindo ou amplificando a sinalização (ATTISANO e LEE-HOEFLICH, 2001). Três tipos de enzimas (E1, E2 e E3) participam dessa proteólise celular, sendo a E3 uibiquitina-ligase, responsável pelo reconhecimento da proteína alvo a ser degradada pelo proteossomo 26S (HERSHKO e CIECHANOVER, 1998). Arkadia, proteína E3 de ubiquitinação, foi reconhecida por promover a amplificação da sinalização de TGF-beta. Arkadia reconhece e leva a degradação, pelo proteassomo 26S, da proteína de inibição da via de sinalização de TGF-beta mediada por Smads, o SMAD7 (KOINUMA, SHINOZAKI et al., 2003). Sabe-se que as células foliculares da glândula tiróide sofrem grande influencia desses fatores de crescimento, sendo expressos mesmo nos cânceres dessa glândula (MATSUO, 2004; GIMENES, 2005; RICARTE-FILHO, 2005). Até o momento, nada se sabe sobre Arkadia nos carcinomas tireoidianos, sendo sua caracterização nessas neoplasias importante no entendimento desses processos patológicos. 


\subsection{TGF-beta e Sinalização Smad}

Os membros da superfamília de TGF-beta se assemelham estruturalmente pela presença de 7 resíduos de cisteínas altamente conservados. Fazem parte desse grupo de proteínas os TGF-betas (transforming growth factor-beta), BMPs (bone morphogenic protein), Nodal, GDF (growth differentiation factor), GDNF (glial cell line-derived neurotrophic factor), MIS (mullerian inhibiting substance), inibinas e activinas. Alguns desses fatores de crescimento compartilham da mesma via de sinalização intracelular, a via dos Smads (MASSAGUE, 1998; PANGAS e WOODRUFF, 2000; MIYAZAWA, SHINOZAKI et al., 2002), como observado na Tabela 1.

Tabela 1: Smads recrutados por membros da superfamília TGF-beta.

\begin{tabular}{|l|c|c|c|}
\hline Fator de crescimento & R-Smad & Co-Smad & I-Smad \\
\hline TGF-beta & SMADs 2 e 3 & SMAD4 & SMAD7 \\
\hline Activina & SMADs 2 e 3 & SMAD4 & SMAD7 \\
\hline BMP & SMADs 1,5 e 8 & SMAD4 & SMADs 6 e 7 \\
\hline Nodal & SMADs 2 e 3 & SMAD4 & SMAD7 \\
\hline MIS & SMADs 1,5 e 8 & SMAD4 & SMAD6 \\
\hline Inibina & SMADs 2 e 3 & SMAD4 & SMAD7 \\
\hline
\end{tabular}

O TGF-beta apresenta cinco isoformas conhecidas até 0 momento, dessas 3 foram identificadas em mamíferos, TGF-beta1, TGFbeta2 e TGF-beta3. TGF-beta1 é a isoforma mais estudada dessa família, sendo sua forma ativa composta por uma proteína dimérica de $25 \mathrm{kDa}$, com cada subunidade composta de 112 aminoácidos (ROBERTS, 1991). O TGF-beta é conhecido como um potente inibidor da 
proliferação de células epiteliais, como hepatócitos, células foliculares tiroidianas, pulmonares, intestinais, da próstata e mama (ROBERTS, 1991; GOLD, 1999; MASSAGUE, BLAIN et al., 2000; MATSUO, LEONI et al., 2006). O TGF-beta atua no bloqueio da progressão da fase 1 do ciclo celular, pelo aumento dos inibidores de cíclina p15, p21 e p27, baixa fosforilação da proteína retinoblastoma e diminuição da expressão do proto-oncogene c-myc (MARKOWITZ, WANG et al., 1995; ATTISANO e LEE-HOEFLICH, 2001).

A activina também é uma proteína dimérica, com cerca de 28 $k D a$, composta por duas subunidades de cadeias $\beta$. Até o momento foram descritos diferentes isotipos de cadeias $\beta$ denominadas $\beta A, \beta B$, $\beta C, \beta D$ e $\beta E$. $A$ isoforma activina $A$, é a mais estudada até o momento e é composta de duas cadeias $\beta A$ com cerca de 116 aminoácidos. Activina A apresenta um efeito inibitório à proliferação celular como observado em células hepáticas, da próstata, mama, hipófise, adrenal e foliculares da tiróide (CHEN, LUI et al., 2002; MATSUO, LEONI et al., 2006).

TGF-beta1 e Activina A se ligam a uma combinação de receptores específicos do tipo I e II com atividade serina-treonina quinase. TGF-beta se liga a seu receptor tipo II (TRRII) leva a fosforilação e ativação do receptor tipo I (TßRI) que desencadeia a sinalização intracelular de TGF-beta via proteínas Smads. Activina ligase ao receptor tipo II (ActRII ou ActRIIB) e esse recruta o receptor tipo I (ActRIB) que propaga a sinalização Smad da mesma forma que ocorre com TGF-beta (PANGAS e WOODRUFF, 2000).

Os receptor regulated SMADs (R-Smads), SMAD2 e SMAD3 são diretamente fosforilados e ativados por T $\beta R I$ e ActRIB. A fosforilação de R-SMADs permite sua interação com common-mediator SMAD (CoSmad), SMAD4, formando um complexo capaz de atingir o núcleo, onde irão modular a transcrição de genes alvo (KAVSAK, RASMUSSEN et al., 
2000; MASSAGUE e WOTTON, 2000; ATTISANO e LEE-HOEFLICH, 2001; EBISAWA, FUKUCHI et al., 2001; MIYAZAWA, SHINOZAKI et al., 2002). Essa sinalização sofre ainda a regulação do Smad inibitório (ISmad), SMAD7, que inibe a fosforilação dos R-Smads pelos receptores TßRI e ActRIB e interfere na formação do complexo R-Smad/Co-Smad diminuindo a sinalização da via de TGF-beta/Activina (HERSHKO e CIECHANOVER, 1998; LANEY e HOCHSTRASSER, 1999 HAYASHI, ABDOLLAH et al., 1997; MASSAGUE, 1998; LEBRUN, et al. 1999; PANGAS e WOODRUFF, 2000; LEBRUN, TAKABE et al., 1999; LIU, NAGARAJAN et al., 2002) A via de sinalização de TGF-beta/Activina mediada por Smads está esquematizada na figura 1. 


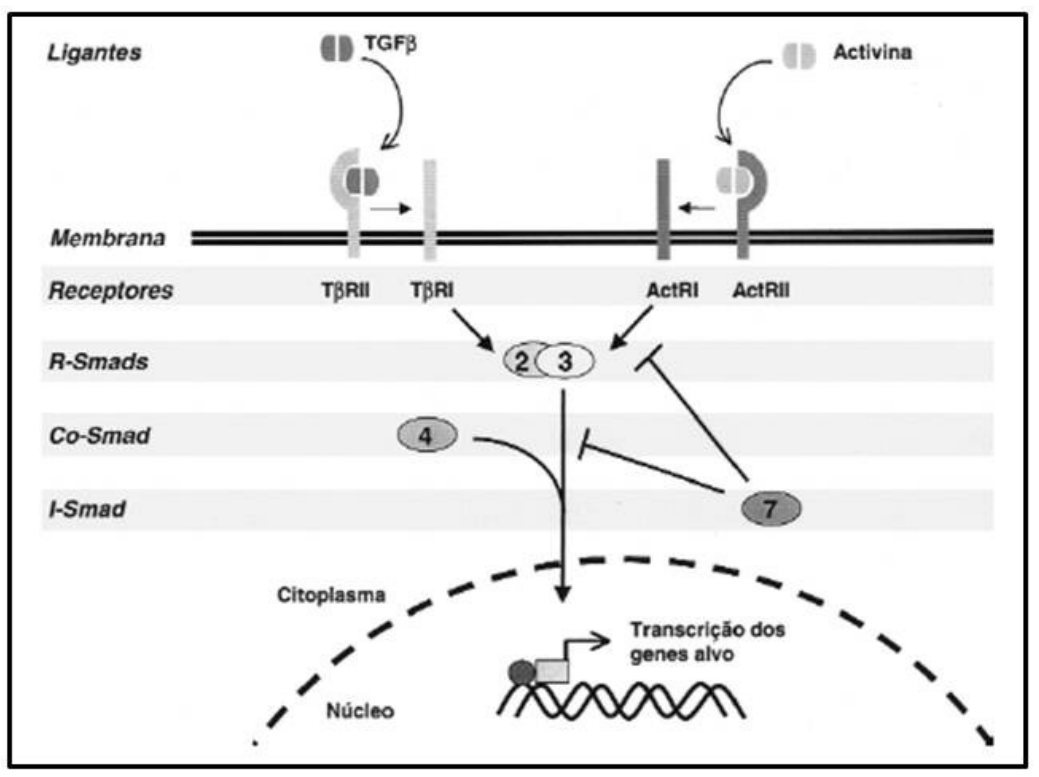

Figura 1: Esquema da sinalização celular de TGF-beta e activina. TGF-beta se liga ao seu receptor de membrana tipo II (TßRII), o qual recruta e ativa o receptor tipo I (TßRI). A activina, por sua vez, se liga ao seu receptor tipo II (ActRII), que irá ativar o receptor tipo I (ActRI). A sinalização intracelular é propagada através de ptoteínas Smads, sendo que SMAD2 e SMAD3 são fosforiladas e ativadas pelos receptores tipo I. A SMAD4 se une à SMAD2/3 fosforilada e este complexo modula a transcrição de genes-alvos no núcleo. A SMAD7 inibe a sinalização de TGF-beta/activina (KIMURA, MATSUO et al., 2007).

As proteínas envolvidas na via de sinalização de TGFbeta/Activina podem sofrer degradação proteolítica pela via de ubiquitinação. Proteínas de ubiquitinação conhecidas como E3 - ligase reconhecem regiões especificas dos Smads e atuam como amplificadoras ou antagonistas do sinal de TGF-beta/Activina (IZZI e ATTISANO, 2004). 


\subsection{Proteólise pela Via de Ubiquitinação}

A degradação protéica dependente de ubiquitinação foi inicialmente descrita por Hershko e Ciechanover em 1998. Este processo está relacionado a diversas funções chaves no controle celular que incluem: sinalização intracelular, progressão do ciclo celular, reparo do DNA, regulação transcricional e endocitose (PRAY, PARLATI et al., 2002).

O processo de proteólise pela via de ubiquitinação ocorre basicamente por dois processos, a marcação da proteína alvo por uma cadeia linear de ubiquitinas, mediada pela ação de três enzimas distintas e a degradação protéica via proteassomo (CIECHANOVER e SCHWARTZ, 1994). A ubiquitina é um poli-peptídeo altamente conservado com 76 aminoácidos e presente em todos os organismos eucariotos (HERSHKO e CIECHANOVER, 1992). A molécula de ubiquitina se torna ativa, quando um resíduo de glicina de sua região C-terminal é adenilada, por um processo dependente de ATP. A ubiquitina ativa forma uma ligação tiolester com E1 - enzima ativadora de ubiquitina. Em processo subseqüente, E1 transfere a ubiquitina ativa para o sítio tiol de E2 - enzima conjugadora de ubiquitina. E2 se liga a E3 - enzima ubiquitina ligase, responsável pelo reconhecimento da proteína alvo. 0 complexo E2-E3-ubiquitina transfere o poli-peptídeo ativo para um grupo amina da proteína alvo (HERSHKO e CIECHANOVER, 1998). O resíduo C-terminal de cada ubiquitina é ligado a uma lisina específica da molécula de ubiquitina precedente produzindo uma série linear de conjugados ubiquitina-ubiquitina (CONAWAY, BROWER et al., 2002). Essa cadeia linear de ubiquitinas é reconhecida por um receptor específico do proteassomo 26S. O proteassomo é um complexo formado a partir de subunidades protéicas, entre elas proteases que clivam a proteína alvo (HERSHKO e CIECHANOVER, 1998; HARTMANN- 
PETERSEN, SEEGER et al., 2003). A molécula de ubiquitina não sofre degradação pelo proteassomo $26 \mathrm{~S}$ e fará parte do processo de ubiquitinação de outra proteína. Figura 2.

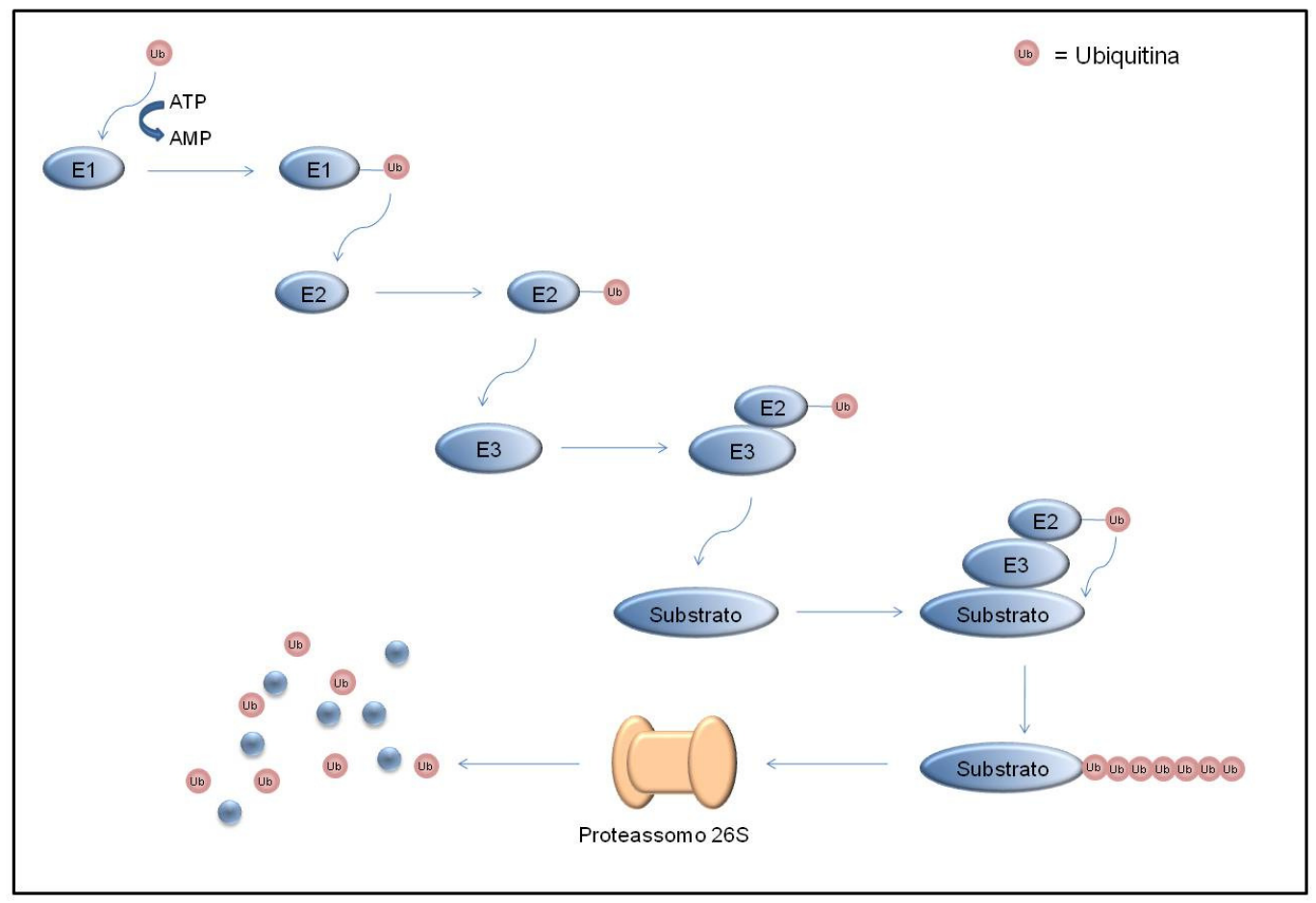

Figura 2: Esquema da proteólise pela via de ubiquitinação. A molécula de ubiquitina se torna ativa por um processo dependente de energia e se liga a enzima ativadora de ubiquitina, E1. E1 transfere a ubiquitina à enzima conjugadora de ubiquitina, E2. E2 se liga a enzima ubiquitina-proteína ligase, E3. E3 reconhece especificamente o substrato a ser degradado (proteína alvo) que receberá a ubiquitina ativa. Quando poliubiquitinada a proteína alvo é reconhecida pelo proteassomo 26S. Após a degradação rotéica, as ubiquitinas que não sofrem nenhum tipo de degradação estão novamente disponíveis para participarem do processo de poliubiquitinação de outras proteínas (HERSHKO e CIECHANOVER, 1998).

As E3 ubiquitina-ligases são divididas em quatro tipos, de acordo com suas características específicas: 
1. HECT (homologous to the E6-AP carboxyl terminus) proteínas HECT apresentam um domínio carboxi-terminal homologo ao domínio carboxi-terminal da primeira proteína identificada, a E6-AP (responsável pela poliubiquitinação de p53), e formam uma ligação tiol intermediária entre a ubiquitina e a proteína alvo, como esquematizado na Figura 3A (SCHEFFNER, HUIBREGTSE et al., 1993; SCHEFFNER, NUBER et al., 1995).

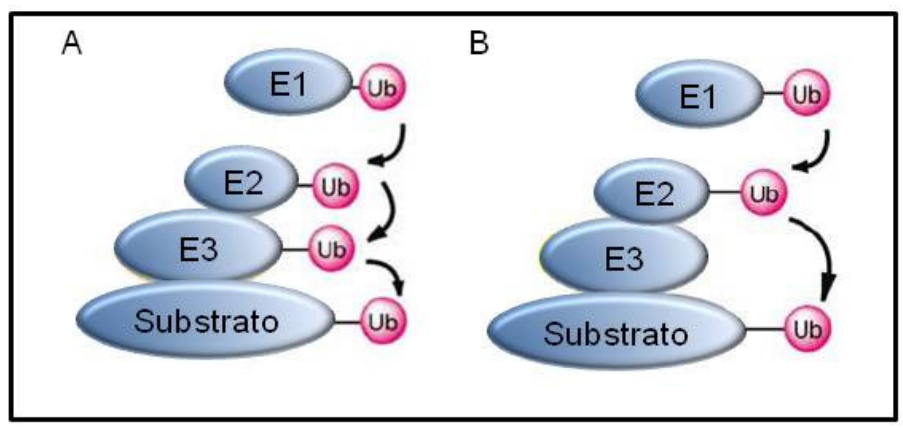

Figura 3: Interação das E3 na via de ubiquitinação. A) E3 forma uma ligação tiol intermediária entre a ubiquitina (Ub) e o substrato. B) E3 não se liga a ubiquitina (Ub), que é transferida diretamente de E2 para o substrato. (esquema adaptado de HATAKEYAMA, 2003).

2. RING-finger (really interesting new gene) - apresentam um octeto de cisteínas e resíduos de histidinas que constituem um domínio de ligação com zinco, são estruturalmente classificadas em RING H2 (com 2 histidinas, uma na posição 4 e outra na posição 5) ou RING HC (com somente uma histidina na posição 4) e não se ligam diretamente a ubiquitina, como exemplificado na figura 3B (LOVERING, HANSON et al., 1993; LORICK, JENSEN et al., 1999).

3. U-box - apresentam uma estrutura tri-dimensional muito semelhante a estrutura das RING-finger, como domínio de ligação com quelato (o quelato consiste de um íon metálico ligado a várias ligações covalentes e uma ligação heterociclica de compostos orgânicos) e não 
se ligam diretamente a ubiquitina (Figura 3B) (HATAKEYAMA e NAKAYAMA, 2003).

4. PHD-finger (plant homeo domain) - também apresentam uma estrutura semelhante a do RING-finger, porém sua região de ligação com E2 é o que a difere daquela classe, também não apresenta ligação direta com a ubiquitina (Figura 3B) (BIENZ, 2006), nenhuma dessas proteínas foi relacionada a via de TGF-beta até o momento.

Proteínas E3 ubiquitina-ligases estão envolvidas na via de sinalização de TGF-beta, algumas inibindo e outras amplificando esta sinalização, SMURFs (do inglês Smad úbiquitination regulatory factor) e CHIP (carboxyl terminus of $\underline{H}$ sp70-interacting protein) são exemplos de antagonistas e Arkadia atua com amplificadora do sinal de TGF-beta (GLASGOW e MISHRA, 2008) (Tabela 2).

Tabela 2: Tipos de E3 da via de sinalização de TGF-beta.

\begin{tabular}{|c|c|c|c|}
\hline E3 & Domínio & Alvo & Função \\
\hline Smurf 1 & HECT & $\begin{array}{c}\text { SMADs } 1 / 4 / 5 / 6 / 7 / 8 \\
\text { T } \beta R I\end{array}$ & Inibe \\
\hline Smurf 2 & HECT & $\begin{array}{c}\text { SMADs } 1 / 2 / 4 / 7 \\
\text { T } \beta R I\end{array}$ & Inibe \\
\hline Arkadia & RING-finger & SMAD 7 & Ativa \\
\hline CHIP & U-box & SMADs $1 / 3 / 4$ & Inibe \\
\hline
\end{tabular}

\subsection{Arkadia}

Em humanos o gene RNF111 que codifica a proteína Arkadia, está localizado no cromossomo $15 q 21$, e é o responsável pela transcrição de uma proteína de 107 kDa. A proteína Arkadia é 
altamente conservada em outros vertebrados como observado na Tabela 3. Arkadia apresenta um domínio NLS (Nuclear Localization Signal) na região N-terminal, responsável por sua localização nuclear, pequenos sítios de ligação com zinco e um domínio RING-H2-finger em sua região C-termial, responsável pela atividade E3 ubiquitina-ligase desta proteína. (EPISKOPOU, ARKELL et al., 2001).

Tabela 3: Comparação entre a sequência de aminoácidos de Arkadia em vertebrados.

\begin{tabular}{lcccc} 
& Arkadia & c-Arakdia & g-Arkadia & x-Arkadia \\
\hline Arkadia & - & & & \\
c-Arkadia & 90 & - & & \\
g-Arkadia & 83 & 83 & - & \\
x-Arkadia & 73 & 73 & 77 & - \\
\hline
\end{tabular}

A porcentagem de aminoácidos em comum entre humanos, camundongos (c-Arkadia), galinha (g-Arkadia) e Xenopus ( $\mathrm{x}-$ Arkadia) (adaptada de EPISKOPOU, 2001).

Arkadia foi inicialmente descrita em 2001 como uma proteína essencial para estabelecer a organização no desenvolvimento de mamíferos. Em embriões, a presença de Arkadia, modula a sinalização do fator de crescimento Nodal (fator de crescimento da família TGF- $\beta$ ), essencial para a formação do endoderma e mesoderma (NIEDERLANDER, WALSH et al., 2001). Camundongos sem a expressão de Arkadia morrem antes do final da gestação, pois apresentam falha no dobramento embrionário, cabeça reduzida, não desenvolvem a placa pré-cordal e notocorda, apresentam a região anterior truncada e raramente se desenvolvem além do $15^{\circ}$ somito (EPISKOPOU, ARKELL et al., 2001). Experimentos realizados em camundongos revelaram que Arkadia é essencial para a expressão do fator HNF3ß (Hepatocyte nuclear factor $\underline{3 \beta}$ ) sem o qual estruturas como o nodo, equivalente ao 
nó de Hensen em embriões humanos que é responsável pelo processo notocordal, e o endoderma anterior definitivo não se formam (NIEDERLANDER, WALSH et al., 2001).

Em 2003, Arkadia foi associada à regulação da via de sinalização de TGF- $\beta$. Essa E3 reconhece e leva a poli-ubiquitinação da proteína Inibitória da via de sinalização de TGF-beta, SMAD7, induzindo sua degradação pelo proteassomo $26 \mathrm{~S}$ e atuando como promotora da amplificação da sinalização de TGF-beta (KOINUMA, SHINOZAKI et al., 2003).

\subsection{Sinalização TGF-beta e câncer}

Em células de origem epitelial, os fatores de crescimento TGFbeta e activina atuam como potentes inibidores da proliferação, porém quando essas células adquirem características malignas ocorrem alterações nos mecanismos que controlam sua proliferação, levando a uma multiplicação descontrolada (MATSUO, LEONI et al., 2006; MASSAGUE, BLAIN et al., 2000; KIMURA, MATSUO et al., 2007). O descontrole da divisão celular observado em tumores hepáticos, coloretais e pulmonares, por exemplo, podem ocorrem por inativação mutacional ou expressão desregulada de componentes da via de sinalização de TGF-beta. Cerca de $13 \%$ dos carcinomas coloretais estão relacionados com erro de replicação ou inativação do receptor TRRII (MARKOWITZ, WANG et al., 1995). SMAD4 foi originalmente descrito como deleted in pancreatic cancer lócus 4 (DPC4), pela alta incidência desta deleção em câncer pancreático (HAHN, 1996; PRAY, PARLATI et al., 2002), posteriormente, observou-se que mutação de SMAD4 também estava presente em tumores coloretais, gástricos, hepáticos e de pulmão (TAKAGI, 1996; POWELL, 1997; YAKICIER, 1999; 
YANAGISAWA, 2000). Mutações em genes que codificam SMAD2 também têm sido encontradas em tumores humanos, tais como hepático, coloretais e de pulmão (EPPERT, 1996; YAKICIER, 1999; YANAGISAWA, 2000). Embora camundongo knockout para o gene de SMAD3 desenvolva câncer coloretal agressivo, mutações do gene de SMAD3 não são observadas em tumores humanos. Até agora somente um relato mostrou ausência de expressão proteica de SMAD3 na leucemia humana (ZHU, 1998; WOLFRAIM, 2004). Splicings alternativos no gene de SMAD4 e no gene PTPN18 (LAZZERESCHI, 2005; GUIMARAES, LATINI et al., 2006) (cuja expressão está relacionada ao gene $E R B B 2$, que quando super expresso em células normais de tiróide de rato, causa resistência ao TGF-beta (MINCIONE, CIRAFICI et al., 1993) também podem levar a alteração na via de sinalização de TGFbeta na tiróide.

Em tumores da tiróide, tanto nos benignos (bócios e adenomas) quanto nos malignos (carcinomas), as isoformas de TGF-beta (TGFbeta1, TGF-beta2 e TGF-beta3) estão altamente expressas em tecidos de tumores da tiróide, quando avaliadas por imunohistoquímica (KIMURA, KOPP et al., 1999). Do mesmo modo há expressão dos receptores de TGF-beta tipo I, tipo II e activina (FRANZEN, PIEK et al., 1999; GIMENES, 2005). Da mesma forma nos tumores malignos e benignos há expressão de membros da via de sinalização Smads, como SMAD2, SMAD3 e SMAD4, sendo a expressão de SMAD7 maior em carcinoma indiferenciado, além da expressão de proteínas E3 de ubiquitinação, Smurfs (CERUTTI, EBINA et al., 2003; MATSUO, 2004; RICARTE-FILHO, 2005). Os elementos necessários para a via de sinalização de TGF-beta mediada por Smads estão presentes nos tumores tireoidianos, indicando que não é a ausência desses fatores a razão pela perda do escape antiproliferativo. 
Até o momento, nada se sabe sobre Arkadia nos carcinomas tireoidianos. A expressão da proteína E3 de ubiquitinação, responsável pela amplificação do sinal gerado por TGF-beta, levando a inibição da proliferação, faz de Arkadia um importante alvo de estudos nas neoplasias da glândula tiróide podendo contribuir no entendimento do papel das proteínas de ubiquitinação nos processos tumorigenicos tireoidianos. 


\section{OBJETIVOS}

Caracterizar a expressão de Arkadia em tumores e linhagens celulares de carcinomas tireoidianos.

Investigar o comportamento da expressão diferencial de Arkadia em clones de linhagem celular ARO:

- Analisando a expressão gênica de membros da via de sinalização Smad e genes relacionados ao ciclo celular responsivos a TGF-beta/activina

- Avaliar a proliferação e viabilidade celular in vitro

- Avaliar a proliferação celular in vivo

- Analisar o efeito do tratamento com proteínas recombinantes de TGF-beta1 e activina $A$ na expressão de genes relacionados a via de sinalização TGF-beta e ao ciclo celular. 


\section{MATERIAIS E MÉTODOS}

\subsection{Tecido de tiróde humana}

Tecidos de tiróide com diagnóstico histopatológico de adenoma folicular, bócio multinodular atóxico (BMN), carcinoma papilífero, carcinoma folicular e carcinoma anaplásico foram obtidos de tiróides removidas cirurgicamente. Todos os tecidos utilizados neste estudo fazem parte do banco de tecidos de nosso laboratório, provenientes de parceria com Hospital Beneficente São Caetano do Sul e aprovado pela Comissão de Ética Médica dos mesmos.

\subsubsection{Processamento dos tecidos para corte histológico}

Os tecidos foram fixados em formol tamponado a $10 \%$. Seguiu-se lavagem em água corrente. Após isto, foram desidratados em banhos de álcool etílico de concentrações crescentes de 50 a 100\%, diafanizados em dois banhos de xilol e impregnados com parafina, utilizando processador Leika. A seguir, os tecidos foram emblocados em parafina e cortados em micrótomo com espessura de $3 \mu \mathrm{m}$. 


\subsubsection{Coloração para hematoxilina e eosina}

Os cortes histopatológicos foram desparafinizados em dois banhos de xilol e reidratados em soluções decrescentes de álcool de 100 a $70 \%$. Em seguida, foram lavados em água corrente e corados com hematoxilina e eosina. Os tecidos foram observados em microscopia de luz para confirmação diagnóstica do fragmento a ser analisado.

3.1.1.2 Expressão protéica de Arkadia nos tecidos tireoidianos humanos.

\subsection{Imuno-histoquímica}

Os ensaios imuno-histoquímicos foram realizados por método imunoenzimático indireto em 3 etapas. Para isto, cortes histológicos com diagnósticos de adenoma folicular $(n=2), B M N(n=4)$, carcinoma papilífero $(n=3)$, carcinoma folicular $(n=2)$, carcinoma anaplásico $(n=4)$ e tecido normal $(n=3)$ foram desparafinizados em banhos de xilol e reidratados com soluções de álcool etílico de concentrações decrescentes de 100 a $70 \%$. Os cortes foram incubados a temperatura ambiente overnight com anticorpo policlonal anti-Arkadia (Santa Cruz Biotechnology, EUA). Posteriormente, os tecidos foram incubados com anticorpo secundário biotinilado anti-goat (Sigma, EUA) por 2 horas, seguido de incubação com estreptoavidina conjugada com peroxidase (Sigma, EUA). Todas as incubações foram diluídas com solução tampão Tris salina (Tris- $\mathrm{HCl} 0,05 \mathrm{M}, \mathrm{pH} 7,6 \mathrm{em} \mathrm{NaCl}$ a 0,88\%) contendo 0,05\% de albumina bovina (BSA) e entre os períodos de incubação, os tecidos 
foram lavados em solução tampão fosfato salina (PBS) $p H=7,4.0$ complexo antígeno-anticorpo foi revelado por solução contendo cromógeno $\mathrm{DAB}$ e $\mathrm{H}_{2} \mathrm{O}_{2}$. A reação foi interrompida por lavagem em água corrente. Em seguida, os tecidos foram contra-corados por imersão dos mesmos em solução de hematoxilina por 20 segundos. 0 controle foi realizado com omissão do anticorpo primário em todos os ensaios.

Apositividade da reação foi observada em microscópio de luz Eclipse E 600 (Nikon, Japão) e analisada segundo critérios de intensidade: fraco $(+)$, moderado $(++)$, forte $(+++)$ e ausente $(-)$.

\section{$\underline{3.2 \text { Cultura celular }}$}

Utilizamos linhagens celular de carcinoma papilífero, folicular e anaplásico de tiróide humana, denominadas NPA, WRO e ARO, respectivamente, doadas pelo $\mathrm{Dr} \mathrm{J}$ A Fagin (Division of Endocrinology and Metabolism, University of Cincinnati College of Medicine, Cincinnati, $E U A)$. As linhagens foram cultivadas em meio RPMI suplementado com $10 \%$ de soro bovino fetal (SBF), $100 \mathrm{U} / \mathrm{mL}$ de penicilina, $100 \mu \mathrm{g} / \mathrm{mL}$ de estreptomicina e $1 \mu \mathrm{g} / \mathrm{mL}$ de anfoterecina e mantida em estufa sob condições de $95 \%$ de ar e $5 \%$ de $\mathrm{CO}_{2}$, a $37{ }^{\circ} \mathrm{C}$.

Linhagem celular de carcinoma de cólon humano, denominada HT29/219, gentilmente doada pela Dra. Alison Colquhoun (Instituto de Ciências Biomédicas da Universidade de São Paulo, originadas do ECACC (European Collection of Cell Cultures). Cultivada em meio DMEN suplementado com $10 \% \mathrm{SFB}, 100 \mathrm{U} / \mathrm{mL}$ de penicilina, $100 \mu \mathrm{g} / \mathrm{mL}$ de estreptomicina e $1 \mu \mathrm{g} / \mathrm{mL}$ de anfoterecina e mantida em estufa sob condições de $95 \%$ de ar e $5 \%$ de $\mathrm{CO}_{2}$, a $37^{\circ} \mathrm{C}$. 


\subsection{Proliferação celular}

\subsubsection{Contagem do número de células}

Células ARO foram semeadas na densidade de $5 \times 10^{4}$ células/poço em placas de 6 poços. As células foram cultivadas por 24, 48 e até $72 \mathrm{~h}$, quando as células atingiram a confluência total. Nos tempos determinados, as células foram tripsinizadas e a contagem de células foi realizada através de uma câmara de Neubauer. O ensaio foi feito em triplicata e a contagem de cada amostra repetida 3 vezes.

\section{$\underline{3.4 \text { Viabilidade celular }}$}

3.4.1 Ensaio de 3-(4,5-dimethylthiazolyl-2)-2,5-diphenyltetrazolium bromide - MTT

MTT é um ensaio colorimétrico quantitativo baseado na clivagem de um sal amarelo tetrazolium (MTT) pela enzima dehidrogenase da mitocôndria e a subseqüente formação de um cristal azul escuro insolúvel que se acumula somente no interior das células viáveis. A quantidade de cor produzida é diretamente proporcional ao número de células viáveis (MOSMANN, 1983).

Células ARO foram semeadas em placa de 96 poços na densidade de $10^{4}$ células/poço e cultivadas até a semiconfluência. MTT (Amresco, EUA) foi adicionado na concentração de $2,5 \mathrm{mg} / \mathrm{mL}$ e incubado por $3 \mathrm{~h}$. Após este período, o meio foi removido e as células 
foram solubilizadas com uma solução de 100 ul de isopropanol/HCL 0,04 M e a leitura do sinal foi realizada em espectrofotômetro (Spectra Max Plus, Molecular Devices, EUA) a $A_{595}$.

3.5 Análise da expressão gênica

3.5.1 RT-PCR quantitativo real time

\subsubsection{Extração de RNA total}

RNA total foi extraído das linhagens, baseado na técnica desenvolvida por CHOMCZYNSKI e SACCHI, em 1987 utilizando-se reagente Trizol (Invitrogen, EUA).

\subsubsection{Transcrição reversa (RT)}

Para gerar DNA complementar (cDNA), cerca de $3 \mu \mathrm{g}$ de RNA total foram incubados na presença de $100 \mathrm{ng} / \mu \mathrm{L}$ de random primers, 10 $\mathrm{U}$ de inibidor de RNase, $1 \mathrm{mM}$ de deoxinucleotídeos trifosfatados (dNTP mix), 10 mM de DTT, tampão de RT $1 x$ e $200 \mathrm{U}$ de M-MLV (Moloney murine leukemia vírus) transcriptase reversa (Invitrogen, EUA) para volume total de $20 \mu \mathrm{L}$. A reação foi colocada à $21{ }^{\circ} \mathrm{C}$ por $10 \mathrm{~min}$, à $42{ }^{\circ} \mathrm{C}$ por $30 \mathrm{~min}$ e à $99{ }^{\circ} \mathrm{C}$ por $10 \mathrm{~min}$ em termociclador Cyclogene (Thecne, Inglaterra). 


\subsubsection{PCR quantitativo real time}

Os primers utilizados para as reações de PCR quantitativo foram desenhados, com base em sequências de referência do GeneBank, usando o programa Primer Express (Applied Biosystems, Inglaterra) e estão listados na Tabela 4. Os primers sense (FWD) e anti-sense (RV) foram escolhidos em éxons distintos para evitar amplificação de DNA genômico. O gene da proteína ribossomal 19 (RPL19) foi utilizado como controle interno de todas as reações.

A concentração de primers foi otimizada para $300 \mathrm{nM}$ de primers. A reação de PCR real time (REIS, OJOPI et al., 2005) foi realizada usando-se $50 \mathrm{ng}$ de $\mathrm{CDNA}, 10 \mu \mathrm{L}$ de SYBR ${ }^{\circledR}$ Green PCR Master Mix () e $300 \mathrm{nM}$ de cada primer em um volume total de $25 \mu \mathrm{L}$, em equipamento Gene Amp ${ }^{\circledR} 5700$ Sequence Detection System (Applied Biosystems, Inglaterra). Cada reação de PCR foi realizada em duplicata, sendo repetida no mínimo duas vezes. Não houve amplificação de gene alvo na ausência de cDNA. Os valores obtidos na reação de PRC real time são expressos em threshold cycle (CT). A expressão de cada gene alvo foi determinada utilizando-se a fórmula

$2^{-\triangle \triangle C T}$ (onde $\triangle C T=C T$ do gene alvo - CT do gene RPL19 e $\triangle \triangle \mathrm{CT}=\triangle \mathrm{CT}$ do TPC experimental $-\triangle \mathrm{CT}$ da amostra controle (PFAFFL, 2001)). 
Tabela 4: Lista de primers utilizados para RT-PCR quantitativo.

\begin{tabular}{ccc}
\hline Gene & Sequência do primer & Gene Bank \\
\hline \multirow{2}{*}{ RNF111 } & FWD:TCAACTGACAGTGAAGTGGAGATTG & NM_017610 \\
& REV:GAGTGTCCAAGGGTTGAACGA & \\
\hline \multirow{2}{*}{ SMAD4 } & FWD:CAGGTGGCTGGTCGGAAA & NM_005359 \\
& REV:AGATCAGGCCACCTCCTCAGA & \\
\hline \multirow{3}{*}{ SMAD3 } & FWD: TCTCCAATGTCAACAGGAATGC & \\
& REV: GAGCCGCACGCCTCTTC & \\
\hline
\end{tabular}

FWD: CCGAAGGCAGACGGTAACA

SMAD2

REV: CCACTGTAGAGGTCCATTCAGATG

NM_005901

\begin{tabular}{lcl}
\hline SMAD7 & FWD: CGATGGATTTTCTCAAACCAACT & \\
& REV: CCCTGTTTCAGCGGAGGAA & \\
\end{tabular}

\begin{tabular}{ccc}
\hline CKS2 & FWD: GGCCAAGCAGATCTACTACTC & NM_001827 \\
& REV: GGGTAACATAACATCCCGGTACTC & \\
\hline MAD2L1 & FWD: CGTGGCCGAGTTCTTCTCA & NM_002358 \\
& REV: AGATGGATAGCCACGCTGAT & \\
\hline MCM6 & FWD: TGCCTGACGTCTCCAAGCTTA & NM_005915 \\
& REV: CATTGACACGGGAATTAGTTCTG & \\
\hline MYC & FWD: TTCGGGTAGTGGAAACCAG & NM_002467 \\
& REV: TCCTGTTGGTGAAGCTAACG &
\end{tabular}


Tabela 4 (Continuação)

\begin{tabular}{ccc}
\hline Gene & Sequência do primer & Gene Bank \\
\hline TGF- $\beta$ & FWD: CGCGTGCTAATGGTGGAAA & NM_000660 \\
& REV: CGGAGCTCTGATGTGTTGAA & \\
\hline PAX-8 & FWD: GGC ATG GTC GCA GGA AGT & NM_003466 \\
& REV: GCG CCA GGC CTC GCT GTA GGA & \\
\hline NKX2-1 & FWD: CAG CCT CCA CCT GAA CT & NM_003317 \\
\hline & REV: ATA GCA AGG TGG AGC AGG ACA T & \\
\hline Rpl19 & FWD: TCTCATGGAACACATCCACAA & NM_000981 \\
\hline
\end{tabular}

Conclusão

3.6 Análise da Expressão protéica

\subsubsection{Western blotting}

Células ARO foram semeadas em placas de $100 \mathrm{~mm}$ e cultivadas até semi-confluência. Em seguida, as células foram retiradas da placa de cultivo e em $1 \mathrm{ml}$ de PBS gelada contendo 10\% de Coquetel Inibidor de Protease (Sigma, EUA) com auxílio de scraper e transferidas para tubos de 1,5 ml. Após centrifugação a $420 \mathrm{~g}$, a solução de PBS foi removida e o botão de células incubado com tampão RIPA (Tris- $\mathrm{HCl} 20$ $\mathrm{mM} \mathrm{pH}=7,5, \mathrm{NaCl} 150 \mathrm{mM}$, Nonidet P-40 1\%, Deoxicolato de Sódio $0,5 \%$, EDTA $1 \mathrm{mM}$ e SDS 0,1\%) e inibidor de protease 10\% (Sigma, 
EUA), por 10 min no gelo. Após centrifugação a $20.800 \mathrm{~g}$ por 5 min a 4 ${ }^{\circ} \mathrm{C}$, o sobrenadante contendo proteínas totais foi coletado e quantificado por método de Bradford, 1976. Quarenta $\mu \mathrm{g}$ de cada amostra foram corridas em SDS-PAGE 10\% (Gel eletroforético de poliacrilamida sódio dodecil sulfato) e transferidas em membrana de nitrocelulose HybondECL (Amersham Bioscience, EUA). Sítios de ligações inespecíficas foram bloqueados por incubações em leite desnatado $5 \%$, em solução salina Tris Buffer com Tween 20 0,1\%. Foram utilizados anticorpos policlonais contra ARKADIA (Abcam, EUA) e a-TUBULINA (Santa Cruz Biotechnology, EUA). Os complexos antígeno-anticorpo foram visualizados utilizando anticorpos secundários contra camundongo conjugado à peroxidase e revelados utilizando kit ECL (Amersham Biosciences, EUA), segundo especificações do fabricante, após exposição da membrana em filme de Raios X. A expressão da proteína TUBULINA foi utilizada como controle do ensaio. $O$ valor densitométrico das bandas foi estimado utilizando o software Scion Image, sendo a expressão de ARKADIA normalizada pela expressão de a-TUBULINA e o valor dado em unidades arbitrárias.

\subsection{Tratamento com proteínas recombinantes de activina A e de TGFß1}

Para avaliar o efeito da adição de proteínas TGF $\beta 1$ e activina A na regulação de genes alvos da sinalização de SMADs e relacionados ao ciclo celular; células ARO foram cultivadas até a semiconfluência, quando foram tratadas ou não com $10 \mathrm{ng} / \mathrm{mL}$ de TGF $\beta 1$ (PeproTech, Rocky Hill, EUA) ou $70 \mathrm{ng} / \mathrm{mL}$ de activina A (PeproTech) por 3h, mantendo-se em meio de cultura RMPI com 10\% SFB. O RNA total destas células foi extraído e o cDNA gerado para reação de PCR quantitativo. 


\section{$\underline{3.8 \text { Xenotransplante }}$}

Camundongos atímicos nude $(\mathrm{n}=3)$ foram mantidos em gaiolas autoclaváveis, sendo alimentados com ração e água autoclavadas ad libitum. Foram injetadas $2 \times 10^{6}$ células em $100 \mu \mathrm{l}$ de PBS (phosphatebuffered saline) subcutaneamente no dorso direito e esquerdo dos animais de 6-8 semanas de idade. O desenvolvimento do tumor foi monitorado a cada 2 dias e os animais foram sacrificados 21 dias após a injeção das células. Os diâmetros perpendiculares dos tumores foram medidos a cada 2 dias a partir do 70 dia do inicio do experimento, utilizando um paquímetro e os volumes calculados pela fórmula da elipsóide rotacional:

$$
\mathrm{V}=\mathrm{A} \times \mathrm{B}^{2} / 2(\mathrm{~A}=\text { diâmetro maior; } \mathrm{B}=\text { diâmetro menor }) .
$$

\subsection{Tratamento com butirato de sódio}

As linhagens HT29 e ARO foram submetidas ao tratamento com butirato de sódio ( $\mathrm{NaBt}$ ), uma vez que esse ácido graxo leva a diferenciação das células HT29. Este tratamento foi proposto uma vez que trabalhos recentes sugerem que a linhagem ARO foi contaminada em sua origem de distribuição pela linhagem HT29. As linhagens foram submetidas ao tratamento por 25 dias, como protocolo descrito em Augeron, 1984. Cada uma das linhagens recebeu dois tipos de meio de cultivo DMEN com $10 \%$ de SFB e RPMI com $10 \%$ SFB, em ambos foram adicionados 5 mM do ácido graxo NaBt para a diferenciação. 


\subsection{Análise estatística}

Os resultados de contagem celular, MTT, Western Blotting, xenotransplante e PCR real time estão apresentados como média \pm desvio padrão (DP) e foram submetidos à análise de variância seguida por teste $\mathrm{t}$ de Bonferroni ou teste Student Newman-Keuls para comparar resultados entre os grupos. Diferenças foram consideradas significantes quando $P<0,05$. 


\section{RESULTADOS}

\subsection{Expressão de Arkadia tecidos de tiróide}

A expressão de Arkadia foi examinada em tecidos provenientes de adenomas, BMN, carcinomas papilíferos, foliculares e anaplásicos e tecidos normais de tiróides. Como observado na Tabela 5, todos os tumores tireoidianos apresentam expressão de Arkadia, somente nos tecidos normais não foi verificada positividade.

Tabela 5. Gradação da positividade dos tecidos submetidos ao ensaio imuno-histoquímico para a proteína ARKADIA

\begin{tabular}{lllcc}
\multicolumn{1}{c}{ Arkadia } & - & + & ++ & +++ \\
\hline Normal $(\mathbf{n = 3})$ & 3 & 0 & 0 & 0 \\
Adenoma $(\mathbf{n = 2})$ & 1 & 1 & 0 & 0 \\
BMN $(\mathbf{n = 4})$ & 1 & 3 & 0 & 0 \\
Papilífero $(\mathbf{n = 3})$ & 1 & 0 & 1 & 1 \\
Folicular $(\mathbf{n = 2})$ & 0 & 1 & 0 & 1 \\
Anaplásico $(\mathbf{n = 4})$ & 0 & 3 & 1 & 0 \\
\hline
\end{tabular}

\subsection{Expressão de Arkadia em linhagens celulares de câncer de tiróide}

Examinamos a expressão gênica de Arkadia em diferentes linhagens celulares de câncer de tiróide: NPA - carcinoma papilífero, WRO - carcinoma folicular e ARO - carcinoma anaplásico ${ }^{1}$ (Figura 4).

\footnotetext{
${ }^{1}$ Em 2008 a identidade das linhagens NPA, WRO e ARO foram questionadas por SCHWEPPE et al.
} 
Observamos que ARO apresenta uma maior expressão gênica desta E3ligase.

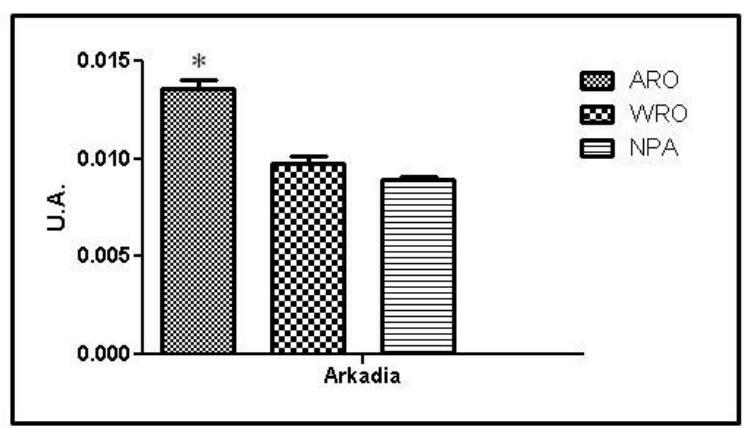

Figura 4: Expressão gênica de Arkadia em linhagens celulares de carcinomas de tiróide. A expressão do gene que codifica Arkadia (RNF111) foi avaliada por PCR- quantitativo e então normalizada pela expressão de RPL19. O gráfico mostra a média \pm DP de experimento realizado em triplicata. $(*) P<0,05$. Unidades Arbitrárias (U.A.).

4.3 Expressão de Arkadia em sub-clones de linhagem celular de carcinoma anaplásico de tiróide

Sabendo que a linhagem ARO apresenta heterogeneidade, instabilidade genômica e potencial de células tronco (MITSUTAKE, IWAO et al., 2007), analisamos dois sub-clones de ARO e observamos que expressavam diferentes níveis de mRNA de ARKADIA (para melhor compreensão dos resultados os sub-clones foram denominados ARO_1 e ARO_2), sendo que ARO_2 apresentou uma expressão gênica 26,8\% maior que ARO_1, como podemos observar na Figura 5.A. Analisando a expressão protéica destes clones observamos que o clone ARO_2 apresenta maior expressão dos níveis de ARKADIA, sendo 27,4\% maior que em ARO_1 (Figura 5.B). 


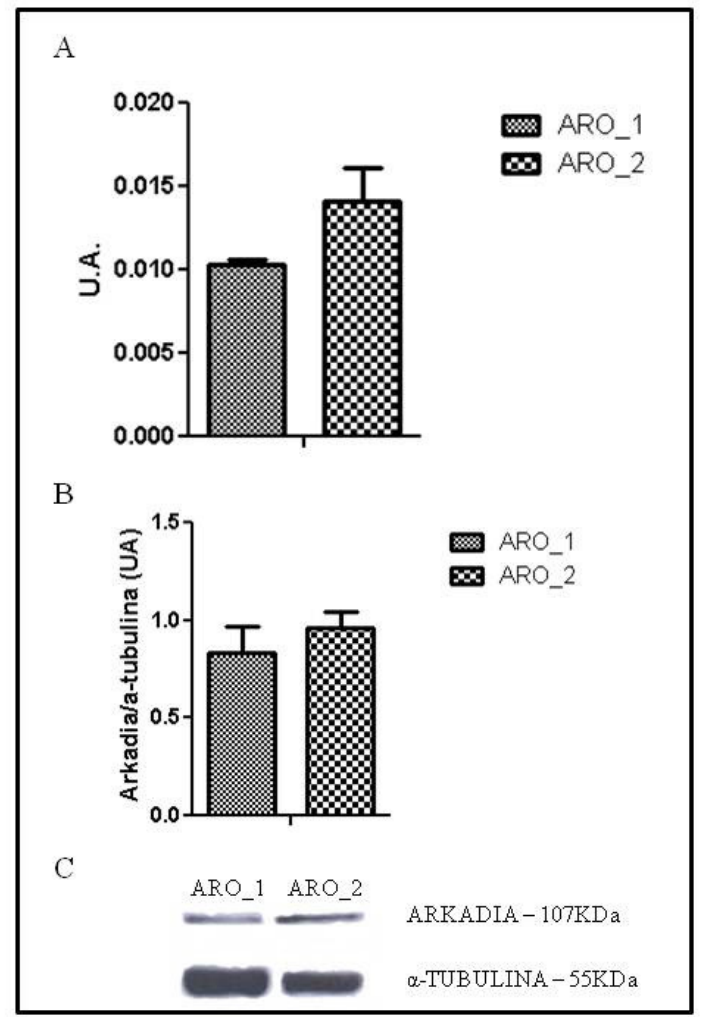

Figura 5: Expressão de Arkadia em linhagem celular de carcinoma anaplásico de tiróide. A) Expressão gênica de $A R K A D I A$, a expressão do gene que codifica Arkadia foi avaliada por PCR quantitativo e então normalizada pela expressão de $R P L 19$. O gráfico representa a média \pm DP de experimento realizado em triplicata. $(*) P<0,05$. B) Expressão protéica de ARKADIA, o gráfico representa média $\pm D P$ da expressão normalizada de ARKADIA/a-TUBULINA. C) Figura representativa do ensaio de Western blotting mostrando a expressão de ARKADIA e a-TUBULINA nos subclones ARO_1 e ARO_2. Unidades Arbitrárias (U.A.). 
4.4 Expressão gênica de membros da sinalização Smads nos clones ARO 1 e ARO 2

Avaliando a expressão de genes envolvidos na via de sinalização de TGF- $\beta /$ Activina SMAD2, SMAD3, SMAD4 e SMAD7, notamos que SMAD3 está 37,8\% e SMAD4 57\% mais expressos em ARO_2, quando comparamos com ARO_1. SMAD7 não apresenta alterações significativas (Figura 6).

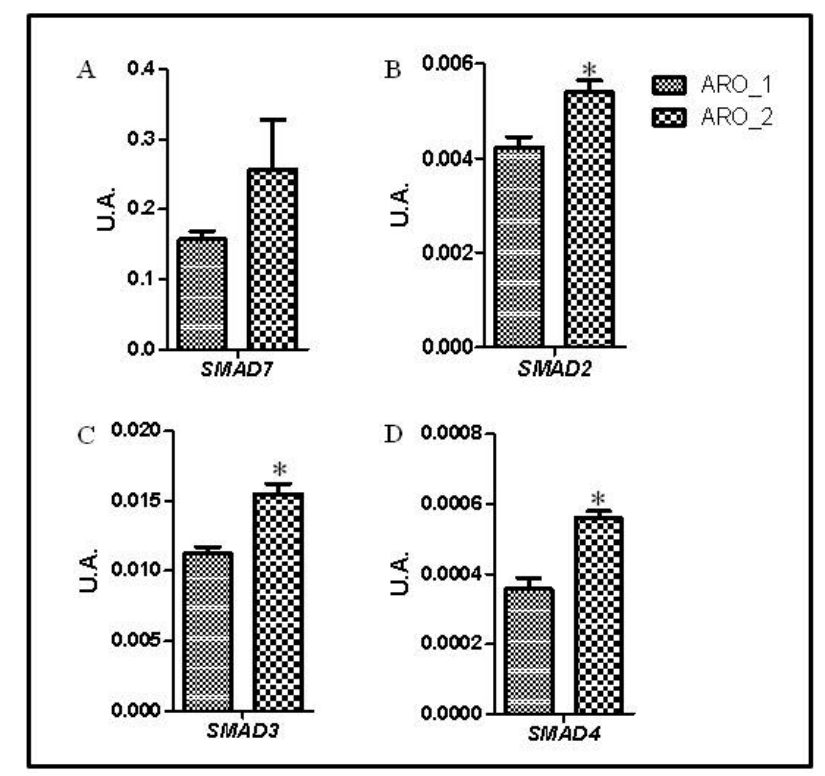

Figura 6: Expressão gênica de linhagem celular de carcinoma anaplásico de tiróide por PCR quantitativo para genes da via de sinalização TGFB/Activina. A) Expressão de SMAD7. B) Expressão de SMAD2. C) Expressão de SMAD3. D) Expressão de SMAD4. A expressão de todos os genes foi normalizada pela expressão de RPL19. O gráfico representa a média \pm DP de experimento realizado em triplicata. (*) $P<0,05$. Unidades Arbitrárias (U.A.).

\subsection{Proliferação in vitro dos clones ARO 1 e ARO 2}

A análise da proliferação celular revelou que o clone com maior expressão de Arkadia apresenta uma menor proliferação celular. A contagem do número de células mostra uma tendência de ARO_1 a uma 
maior proliferação (Figura 7.A), porém quando realizamos o teste MTT não observamos diferença na viabilidade dos dois clones (Figura 7.B). Os resultados obtidos na contagem do número de células não apresentam diferenças significativas, no entanto, nos três ensaios realizados do mesmo experimento notamos uma tendência a maior proliferação de ARO_1.

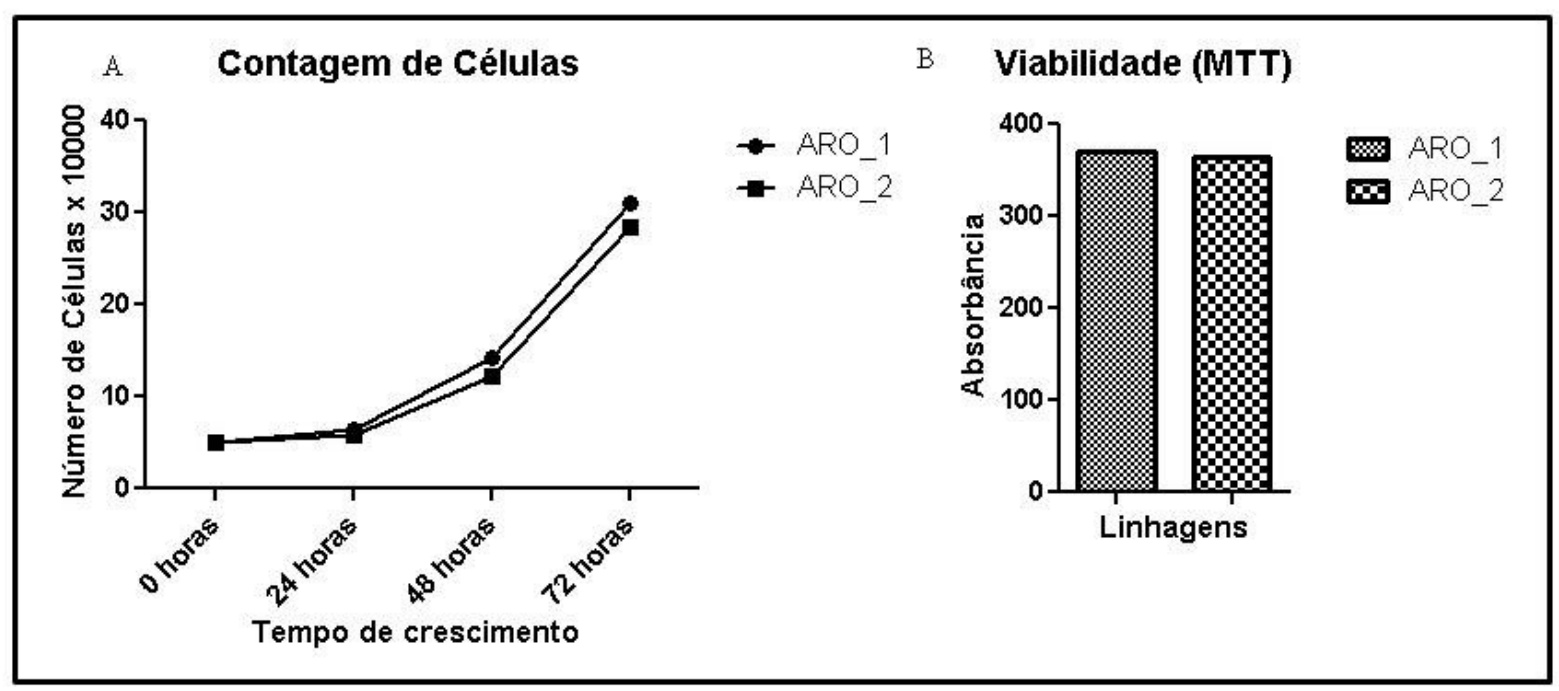

Figura 7: Ensaios de proliferação in vitro em linhagem celular de carcinoma anaplásico de tiróide. A) Contagem de células em câmara de Neubauer. As células foram semeadas na densidade de $5 \times 10^{4} \mathrm{em}$ placas de 6 poços e a contagem das células foi realizada nos tempos indicados. B) Ensaio de viabilidade celular. As células foram semeadas a igual densidade em placas de 96 poços e cultivadas até semiconfluência, quando foram incubadas com MTT por 3 horas. Os gráficos representam a média \pm DP de experimento realizado em triplicata.

\subsection{Proliferação in vivo dos clones ARO 1 e ARO 2}

Ao analisar o crescimento tumoral pelo ensaio de xenotransplante notamos que o clone ARO_2, com maior expressão de Arkadia apresenta um potencial de formação tumoral menor quando comparado com o clone ARO_1 a partir do 90 dia de observação (Figura 8). 


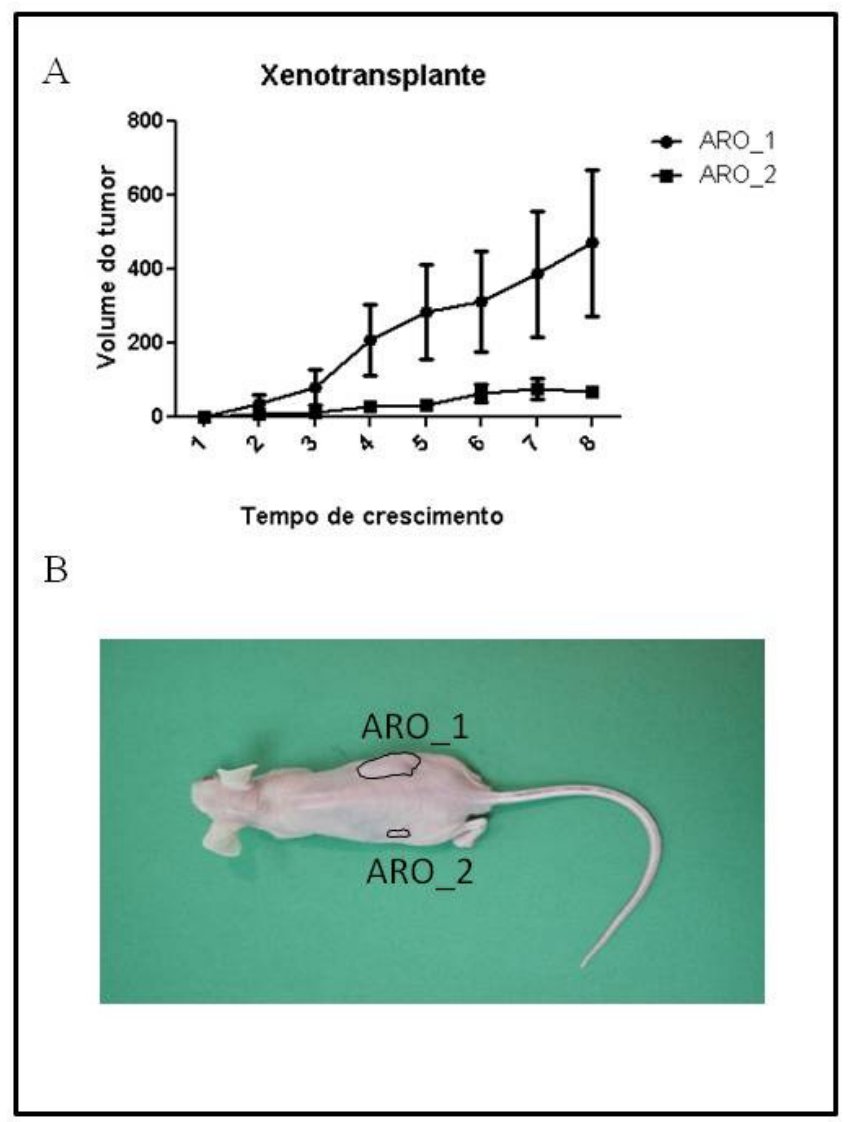

Figura 8: Crescimento tumoral da linhagem de carcinoma anaplásico de tiróide em camundongos atímicos. A) Aumento do volume tumoral comparado entre os clones ARO_1 e ARO_2. B) Foto representativa dos tumores no dia do sacrifício. O gráfico representa a média \pm DP de experimento realizado em triplicata. $* P<0,05$.

4.7 Expressão de genes envolvidos com o ciclo celular nos clones ARO 1 e ARO 2

Realizamos a analise da expressão de alguns genes do ciclo celular, responsivos a TGF-beta. A análise da expressão gênica das linhagens mostra diferença na expressão de todos os genes avaliados (Figura 9), porém a expressão de C-MYC (Figura 9D), P21 (Figura 9E) e P27 (Figura 9F) não apresentam diferenças significativas. O aumento observado foi de 76,7\% em CKS2 (Figura 9C), 42,8\% em MAD2 (Figura 
9B) e 47,2\% em MCM6 (Figura 9A), em ARO_2 quando comparado a ARO_1.

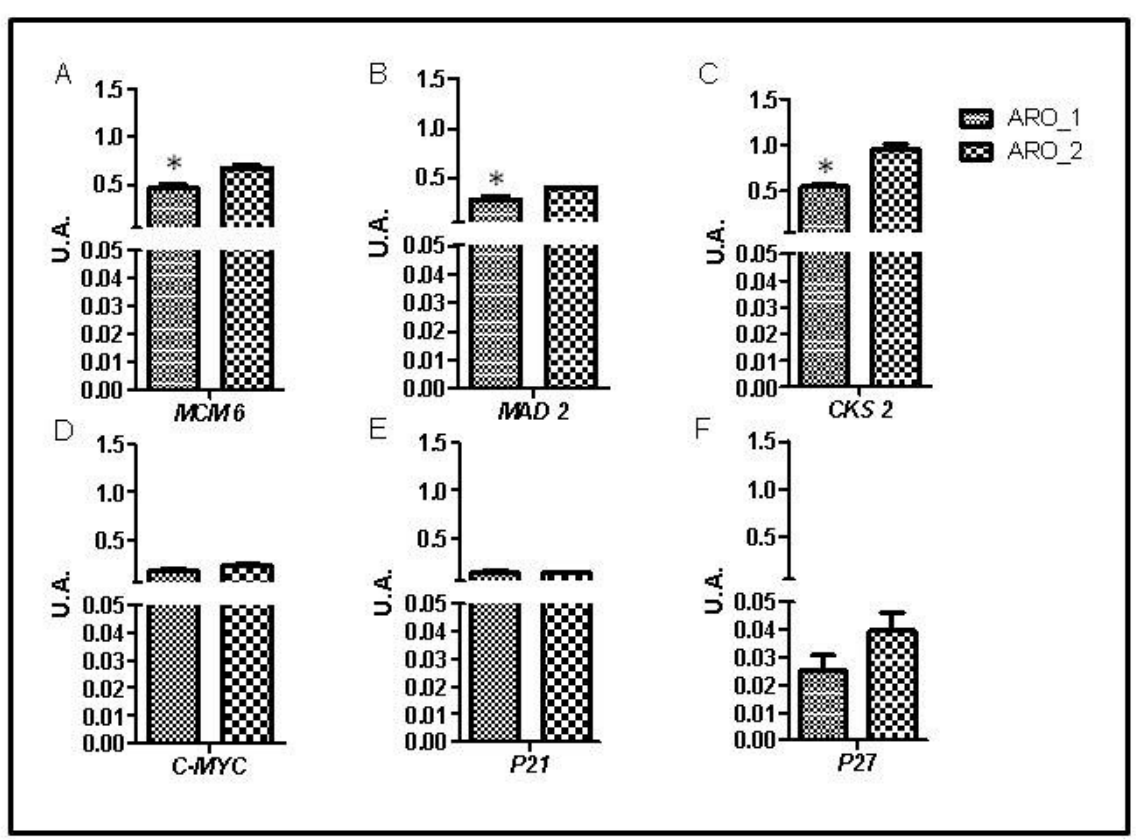

Figura 9: Expressão gênica de linhagem celular de carcinoma anaplásico de tiróide por PCR quantitativo para genes envolvidos com o ciclo celular. A) Expressão de MCM6. B) Expressão de MAD2. C) Expressão de $C K S 2$. D) Expressão de C-MYC. E) Expressão de $P 21$. F) Expressão de $P 27$. A expressão de todos os genes foi normalizada pela expressão de RPL19. O gráfico representa a média \pm DP de experimento realizado em triplicata. $(*) P<0,05$. Unidades Arbitrárias (U.A.).

\subsection{Tratamento de ARO 1 e ARO 2 com TGF- $\beta 1$ e activinaA}

Para avaliar o efeito do fator de crescimento TGF- $\beta$ nos clones ARO_1 e ARO_2, $10 \mathrm{ng} / \mathrm{ml}$ de TGF- $\beta 1$ foram adicionados ao meio de cultivo das células. A análise mostra que a expressão de todos os genes avaliados é diminuída pelo tratamento, como podemos observar na Figura 10, além disso, notamos que os níveis de expressão gênica de CKS2, MCM6 e TGF- $\beta$ estão maiores no clone ARO_1, (sendo 32,3\% maior em CKS2, 26,2\% maior em MCM6 e 51,9\% maior em TGF- $\beta$ ). Observamos também que os níveis de expressão gênica de C-MYC 
apresenta-se maior em ARO_2 tratado com TGF- $\beta$. Os níveis de MAD2, SMAD7 e ARKADIA não apresentam diferenças significativas.

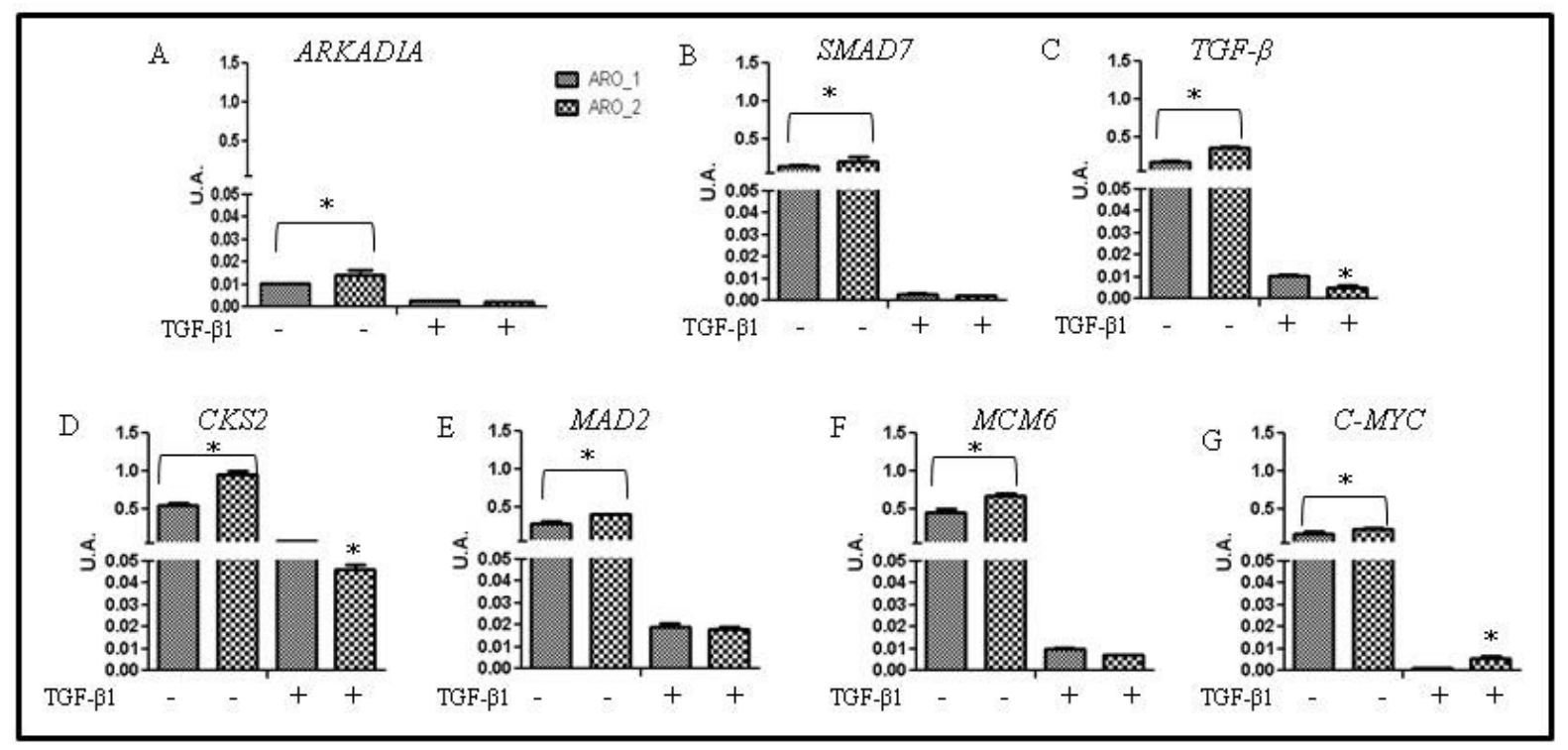

Figura 10: Expressão gênica de linhagem celular de carcinoma anaplásico de tiróide tratada com TGF- $\beta 1$, por PCR quantitativo. A) Expressão de ARKADIA. B) Expressão de SMAD7. C) Expressão de TGF- $\beta$. D) Expressão de $C K S 2$. E) Expressão de MAD2. F) Expressão de MCM6. G) Expressão de C-MYC. A expressão de todos os genes foi normalizada pela expressão de RPL19. O gráfico representa a média \pm DP de experimento realizado em triplicata. $(*) P<0,05$. Unidades Arbitrárias (U.A.).

Para avaliar o efeito do fator de crescimento activina nos clones ARO_1 e ARO_2, $70 \mathrm{ng} / \mathrm{ml}$ de activina A foram adicionados ao meio de cultivo das células. Observamos que a expressão gênica é diminuída pelo tratamento com activina $A$ assim como acontece com o tratamento de TGF- $\beta 1$. A expressão de MCM6 é 48,08\% maior em ARO_1 quando comparada a ARO_2. C-MYC e TGF- $\beta$ apresentam-se mais expressos em ARO_2 que em ARO_1, já a expressão de CKS2, MAD2, SMAD7 e ARKADIA não sofreram alterações significativas (Figura 11). 


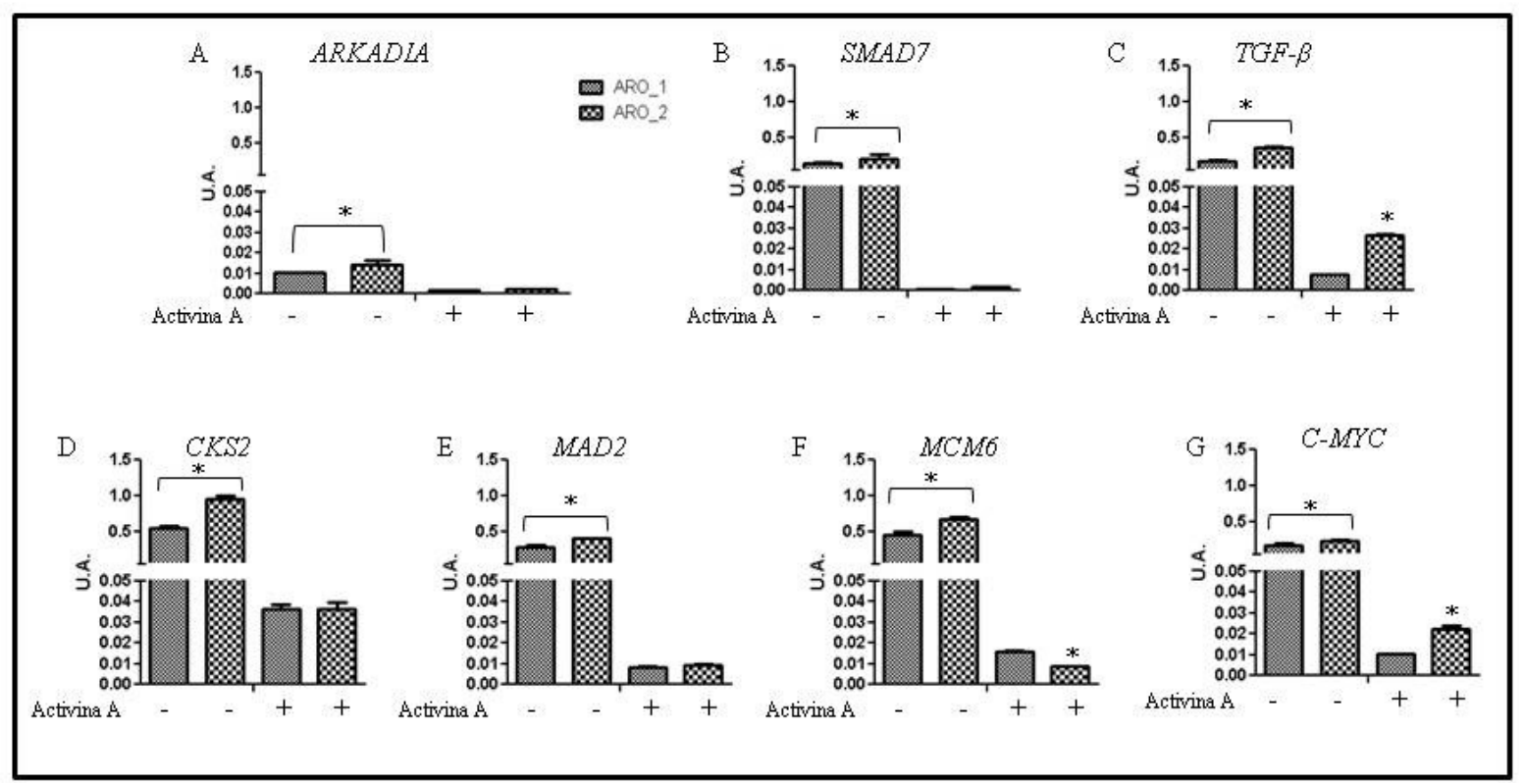

Figura 11: Expressão gênica de linhagem celular de carcinoma anaplásico de tiróide tratada com activina $\mathrm{A}$, por PCR quantitativo. A) Expressão de ARKADIA. B) Expressão de SMAD7. C) Expressão de TGF- $\beta$. D) Expressão de $C K S 2$. E) Expressão de MAD2. F) Expressão de MCM6. G) Expressão de C-MYC. A expressão de todos os genes foi normalizada pela expressão de RPL19. O gráfico representa a média \pm DP de experimento realizado em triplicata. $\left(^{*}\right) P<0,05$. Unidades Arbitrárias (U.A.).

4.9 Caracterização da linhagem celular de carcinoma anaplásico de tiróide - ARO

\subsubsection{Expressão gênica de Arkadia}

A análise da expressão gênica de $A R K A D I A$ revelou que a linhagem ARO expressa 93,08\% mais Arkadia que a linhagem HT29, como apresentado no gráfico da Figura 12. 


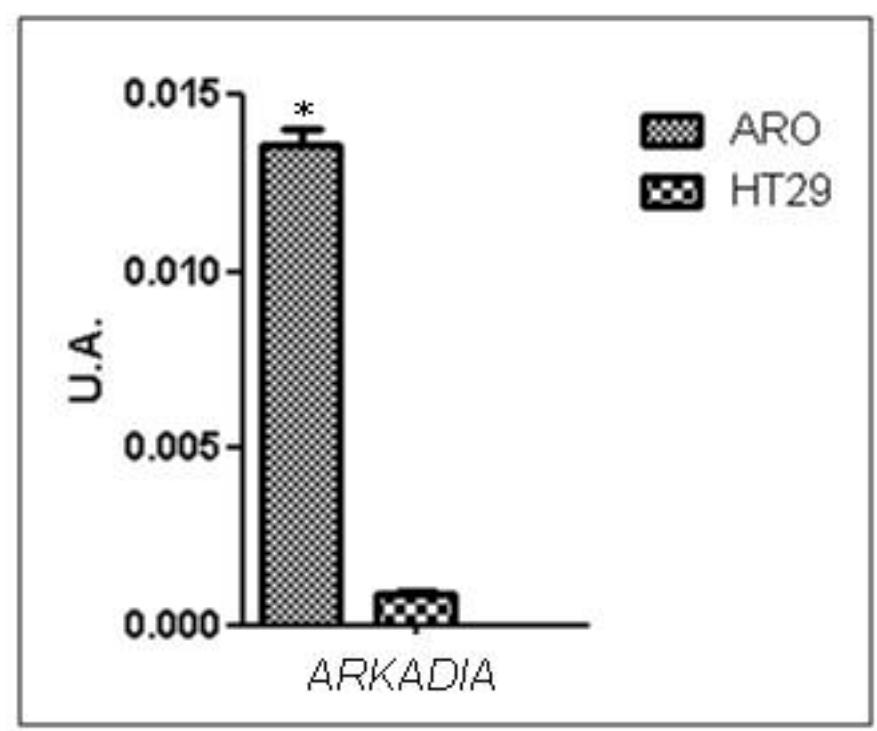

Figura 12: Expressão gênica de Arkadia em linhagem celular ARO e HT29, por PCR quantitativo. A expressão do gene de Arkadia (RNF111) foi normalizada pela expressão de RPL19. O gráfico representa a média \pm DP de experimento realizado em triplicata. (*)P<0,05. Unidades Arbitrárias (U.A.).

\subsubsection{Expressão gênica de $P A X-8$ e TTF-1}

A expressão de genes de diferenciação tiroidiana $P A X-8$ e TTF-1 foi analisada nas linhagens ARO e HT29, podemos observar que tanto a expressão de $P A X-8$ (Figura 13.A) quanto a expressão de TTF-1 (Figura 13.B) é maior na linhagem ARO quando comparada com a linhagem HT29. 

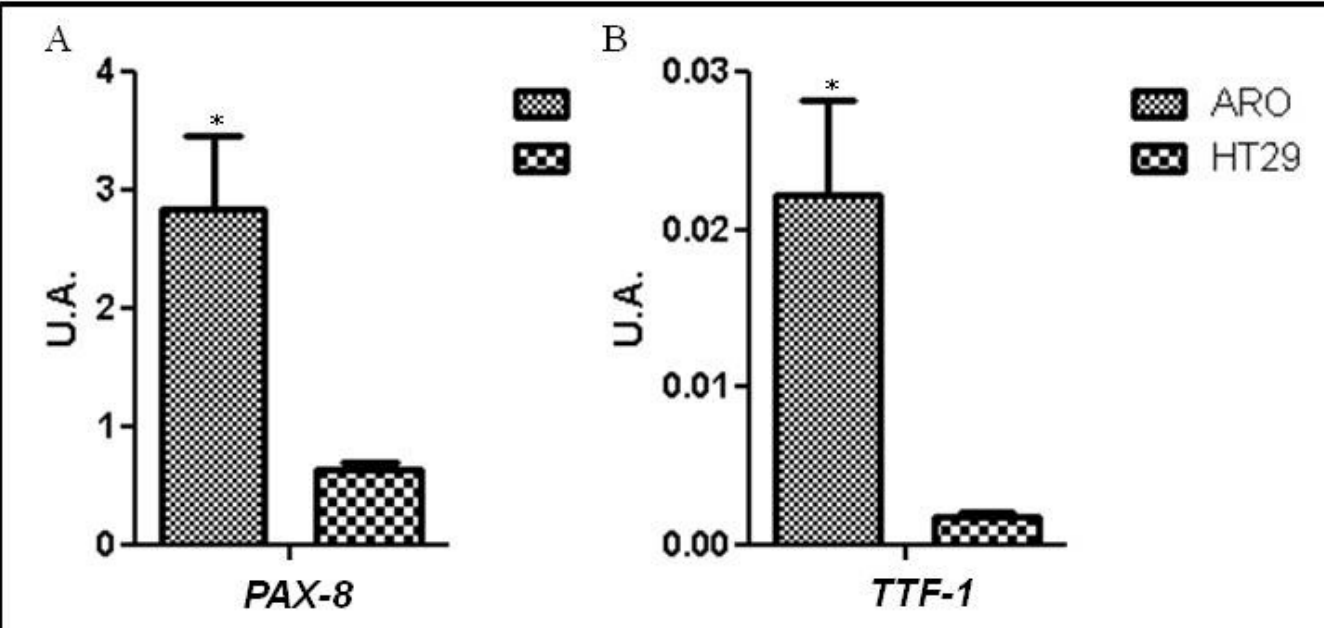

Figura 13: Expressão de genes de diferenciação tiroidiana nas linhagens ARO e HT29, por PCR quantitativo. A) Expressão gênica de $P A X-8$. B) Expressão gênica de TTF-1. A expressão dos genes avaliados foi normalizada pela expressão de $R P L 19$. O gráfico representa a média \pm DP de experimento realizado em triplicata. $(*) P<0,05$. Unidades Arbitrárias (U.A.).

\subsubsection{Diferenciação com butirato de sódio}

Nos primeiros dias de tratamento para diferenciação com butirato de sódio ( $\mathrm{NaBt}$ ) não foi observada diferença morfológica entre as linhagens ARO e HT29 (Figura 14 - $2^{\circ}$ Dia), a partir do 40 dia de tratamento começam a aparecer diferenças morfologia entre as duas linhagens, como observado até a realização da primeira passagem, no $11^{\circ}$ dia de tratamento, após a tripsinização as células apresentaram forma muito semelhantes, porém esse evento não se mantém nos dias seguintes (Figura 15). Ao final do $24^{\circ}$ dia de tratamento as células sofreram nova passagem o tratamento foi suspenso e as linhagens cultivadas em meio contendo apenas $10 \%$ de SFB, novamente, após a tripsinização, as linhagens apresentaram morfologia muito semelhante e voltaram a apresentar diferenças morfológicas até do $33^{\circ}$ dia onde as linhagens sofreram nova passagem (Figura 16). Após a terceira 
passagem as linhagens persistiram com as diferenças morfológicas (Figura $16-370 \mathrm{dia}$ ).

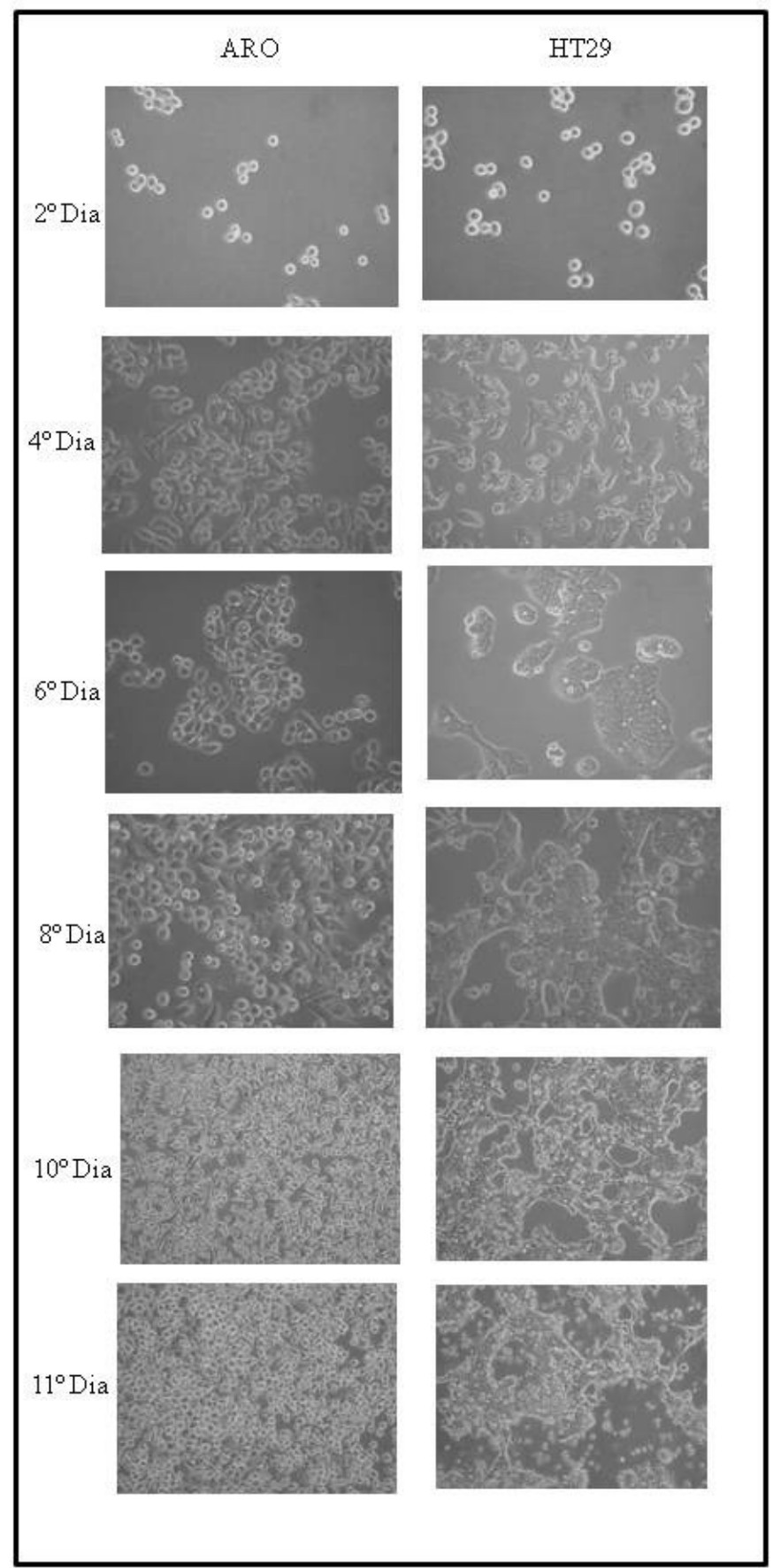

Figura 14: Linhagens ARO e HT29 tratadas com butirato de sódio. Foram plaqueadas 2 milhões de células em garrafas de $25 \mathrm{~cm}^{2}$, no segundo dia de cultivo as células receberam meio de cultivo com $5 \mathrm{mM}$ de Butirato de Sódio, o meio foi substituído a cada 2 dias e tripsinizadas no $11^{\circ}$ dia. 


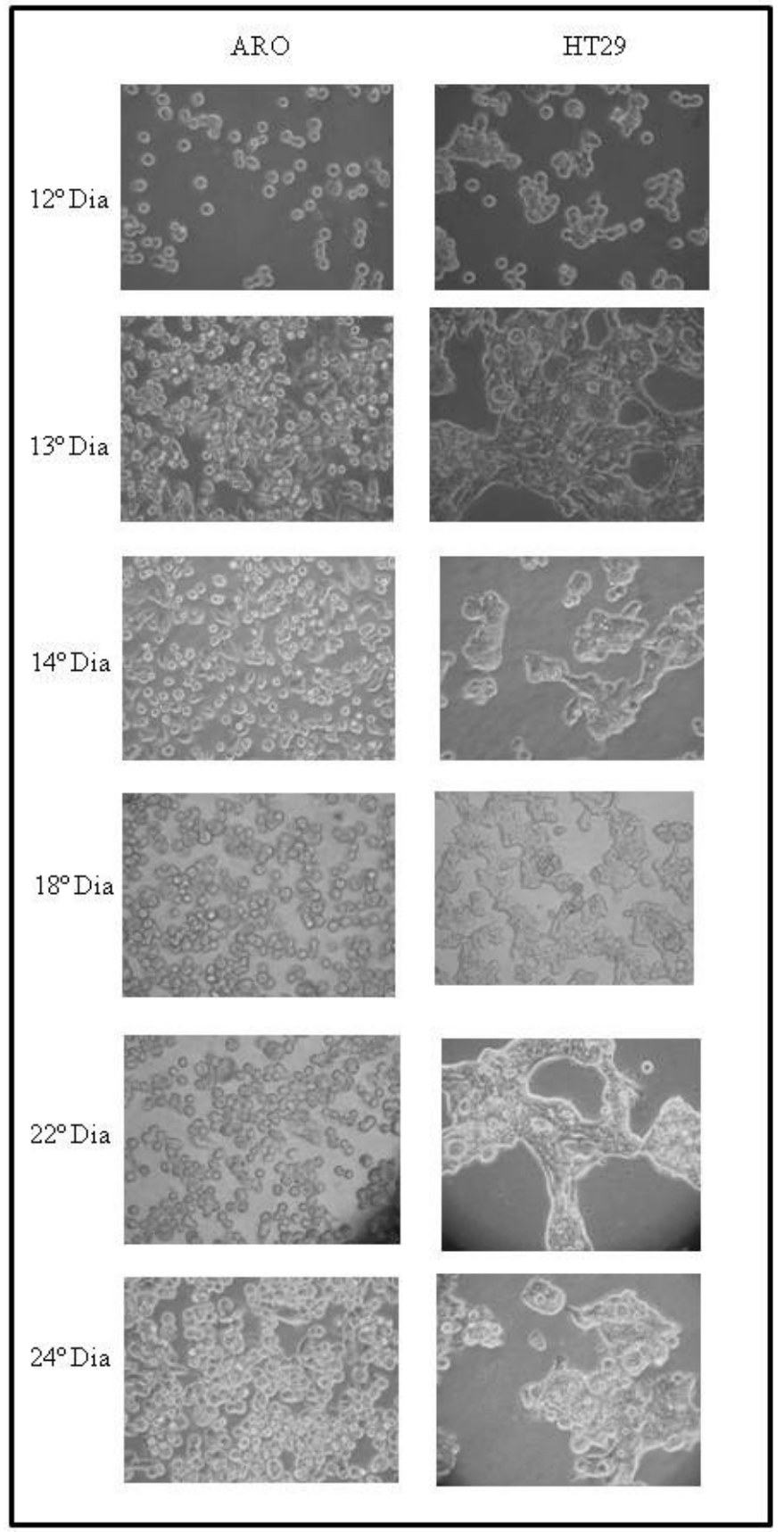

Figura 15: Linhagens ARO e HT29 tratadas com butirato de sódio após a primeira passagem. As células receberam meio de cultivo com $5 \mathrm{mM}$ de butirato de sódio, sendo substituído a cada 2 dias e tripsinizadas ao final do $24^{\circ}$ dia. 


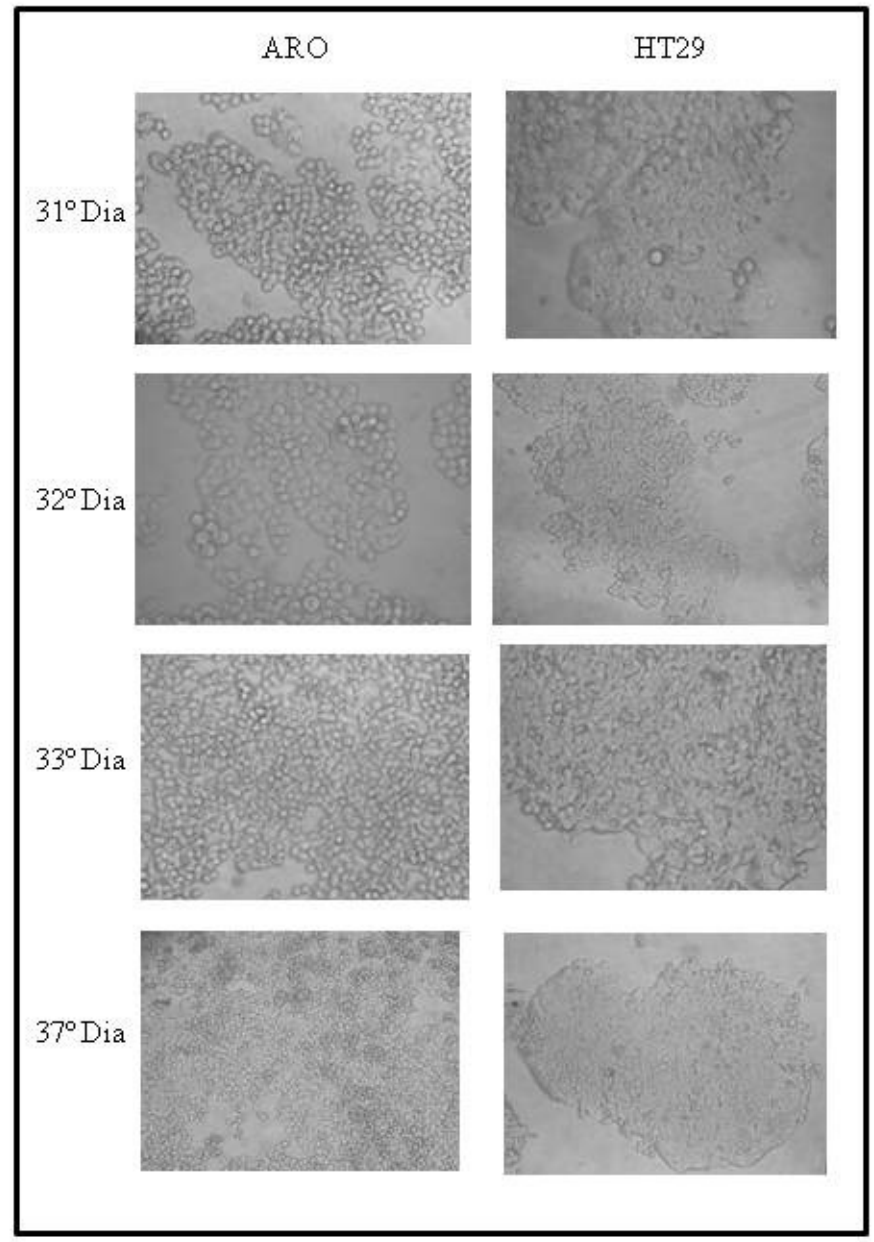

Figura 16: Linhagens ARO e HT29 após tratamento com butirato de sódio. Ao final do tratamento as células foram plaqueadas em garrafas de 25 $\mathrm{cm}^{2}$, e cultivas com meio de cultivo contendo apenas $10 \% \mathrm{SFB}$, sendo substituído a cada 2 dias. 


\section{DISCUSSÃO}

O presente estudo avaliou a expressão de Arkadia, proteína E3 da via de ubiquitinação, em tumores de tiróide. Nossos dados mostram que linhagens celulares de tumores humanos diferenciados (carcinomas papilífiero e folicular) e indiferenciados (carcinoma anaplásico) apresentam expressão gênica de Arkadia, e que essa expressão é maior em linhagem de carcinoma anaplásico de tiróide (Figura 4). Dados imunohistoquímicos também indicam que tumores tiroidianos apresentam expressão de Arkadia (Tabela 5). A expressão de SMAD2, SMAD3, SMAD4 e SMAD7 em tumores benignos e malignos da tiróide e a expressão dos receptores de TGF-beta e activina nestes tumores indicam que mesmo em processos tumorigenicos a presença dos membros da via de sinalização de TGF-beta/activina são expressos e a presença de Arkadia, proteína amplificadora desta via de sinalização, estaria favorecendo o papel inibitório de TGF-beta/activina (FRANZEN, PIEK et al., 1999; CERUTTI, EBINA et al., 2003; MATSUO, 2004; GIMENES, 2005).

Em nosso trabalho pudemos observar que a expressão de Arkadia é maior em linhagem de carcinoma anaplásico (Figura 4), Cerutti e colaboradores (2003) observaram que neste carcinoma indiferenciado a expressão do Smad inibitório também é maior em relação aos outros carcinomas avaliados. Arkadia que tem como alvo SMAD7 atuaria, em ARO, compensando a inibição gerada por esse Smad, além de auxiliar na amplificação da sinalização de TGF-beta/activina.

Recentemente, Mitsutake e colaboradores (2007) mostraram que a linhagem celular ARO apresenta células periféricas, também chamadas células SP (side populations cells). As células SP se caracterizam por apresentarem diferença na expressão de genes, 
grande potencial de formação tumoral, resistência a drogas e características de células tronco de câncer - CSC (çancer stem cell), Takano e colaboradores têm sugerido que existe relação entre células tronco e a carcinogênese da tiróide (PARDAL, CLARKE et al., 2003;TAKANO e AMINO, 2005; WICHA, LIU et al., 2006; TAKANO, 2007; TAKANO, ITO et al., 2007). Nosso estudo observou a presença de subclones de ARO com expressão gênica (Figura 5A) e protéica (Figuras 5B e 5C) diferenciada de Arkadia, que foram denominados ARO_1 e ARO_2 (sendo ARO_2 > ARO_1), estes modelos foram utilizados em nosso estudo para entender o comportamento de Arkadia em carcinoma anaplásico da tiróide.

Observamos que na linhagem celular de carcinoma anaplásico de tiróide os subclones ARO_1 e ARO_2 apresentam expressão diferenciada dos níveis de RNAm dos membros da via de sinalização Smad (Figura 6). O subclone ARO_2, que apresenta maior expressão de Arkadia, apresenta também maior expressão dos R-Smads (SMAD2 e SMAD3) e Co-Smads (SMAD4). SMAD7 (Smad Inibitório) ao mesmo tempo está mais expresso em ARO_2, porém esses dados não são significativos. Levy e colaboradores (2007) têm mostrado que a inibição da proteína de ubiquitinação Arkadia modula a transcrição induzida por TGF- $\beta$, de maneira semelhante à inibição de outros membros da via como SMAD3, SMAD4 e sugerem que sob o estímulo de TGF-beta, PSMAD2/3 interagem com Arkadia presente no núcleo levando a poliubiquitinação de SnoN, proteína que regula negativamente a sinalização de TGF- $\beta$ /Activina. Baseado nestes dados poderíamos supor que em ARO_2 a via de sinalização mediada por Smads estaria exercendo melhor sua função anti-proliferativa, uma vez que neste clone os níveis de Arkadia, Co-Smads e R-Smad são maiores. Uma vez que R-Smads podem interagir com Arkadia no núcleo, levando a poliubiquitinação de SnoN e o fato de não observamos diferença 
significativa na expressão de Smad7 nos levam a considerar que, ora Arkadia levaria a degradação de SMAD7, ora a degradação de SnoN.

Nossos dados de proliferação in vitro não revelam diferenças entre ARO_1 E ARO_2. A viabilidade avaliada por MTT não sofre alteração entre os dois clones (Figura 7B), assim como a contagem de células em câmara de Neubauer (Figura 7A), mesmo observando que o clone ARO_2, com maior expressão de Arkadia, apresenta sempre um menor número de células, em comparação ao clone ARO_1 essa diferença não foi significativa. Mitsutake e colaboradores, 2007 observaram que o crescimento in vivo de células SP e não SP da linhagem ARO é muito semelhante, não apresentando diferenças entre as populações avaliadas. Constatamos, desta forma, em nosso estudo, que mesmo observando expressão gênica diferenciada, estes subclones apresentam o mesmo comportamento frente a proliferação in vitro.

Por outro lado, os experimentos in vivo (Figura 8) mostram que os subclones ARO_1 e ARO_2 apresentaram formação tumoral em camundongos atímicos xenotransplantados. O subclone ARO_2, que apresenta maior expressão de Arkadia e dos membros da via de sinalização Smad apresenta menor potencial de formação tumoral. Estudos in vivo realizados com linhagens que apresentavam características de CSC evidenciam que essas apresentam um maior potencial de formação tumoral quando injetadas em camundongos atímicos, na linhagem ARO observou-se que tanto as células SP quanto as não SP possuíam potencial de formação tumoral (PARDAL, CLARKE et al., 2003; MITSUTAKE, IWAO et al., 2007). Zito e colaboradores (2008) mostraram que células da linhagem ARO apresentam a expressão de CD133 que tem sido utilizado para identificação de CSC em diversos cânceres humanos (YIN, MIRAGLIA et al., 1997). As células ARO positivas para CD133 apresentam um maior potencial tumoral (ZITO, 2008). Em nosso trabalho, o menor crescimento tumoral apresentado por ARO_2 pode estar diretamente relacionado ao fato de 
Arkadia amplificar a via de TGF- $\beta$, auxiliando na inibição da proliferação (KOINUMA, SHINOZAKI et al., 2003).

Os genes MCM6 (minichrosome maintenance deficient $\underline{6}$ ), associado a duplicação de DNA, MAD2L1 (MAD2 mitotic arrest deficientlike 1), responsável pela transcrição da proteína MAD2L1 envolvida no controle da mitose, garantido a separação correta das cromátides irmãs durante a anáfase, e CKS2 (CDC28 protein kinase regulatory subunit 2) foram associados a activina por Matsuo em 2005, quando membrana de array, contendo 96 genes envolvidos na regulação do ciclo celular, foi hibridizada com sonda de cDNA de TPC (linhagem de carcinoma papilífero de tiróide) com e sem RNAi para activina (ISHIMI, 1997; HARPER, 2001; FANG, 2002; WANG, JIN et al., 2002). Pelo fato de muitos autores sugerirem que o carcinoma anaplásico seja uma evolução dos carcinomas diferenciados da tiróide, investigamos a expressão desses genes modulados por activina em carcinoma papilífero, nos subclones ARO_1 e ARO_2 (SPIRES, SCHWARTZ et al., 1988; FAGIN, MATSUO et al., 1993; FAGIN, 1994; NIKIFOROVA et al., 2003; ARE e SHAHA, 2006). MCM6, MAD2L1 e CKS2 são mais expressos no subclone ARO_2 do que no subclone ARO_1 (Figura 9A, 9B e 9C), esse dados indicam que em ARO_2 haveria mais proliferação que em ARO_1, porém isso não é observado em nosso experimento de proliferação in vivo, mostrando que outros genes poderiam modular a regulação do ciclo celular nos subclones de ARO.

Avaliamos ainda a expressão do gene C-MYC cuja transcrição é inibida pelos fatores de crescimento TGF- $\beta$ e activina e os genes responsáveis pelas proteínas p21 e p27 conhecidas como inibidoras de CDK, que são modulados por TGF- $\beta$, porém os subclones analisados não apresentaram alterações significativas para esses genes (Figura 9D, 9E e 9F) (ATTISANO e LEE-HOEFLICH, 2001; MIYAZAWA, SHINOZAKI et al., 2002; MIYAZONO, SUZUKI et al., 2003). 
Pouco se sabe sobre o efeito da adição de proteínas recombinantes de TGF- $\beta$ e Activina em linhagem celular de carcinoma anaplásico de tiróide humano. Nossa investigação mostrou que o tratamento com esses fatores de crescimento, individualmente, modulou a expressão de genes envolvidos com o ciclo celular assim como de membros da via de TGF- $\beta$ (Figuras 10 e 11). Interessantemente, observamos um aumento nos níveis de C-MYC no clone ARO_2 quando tratados com TGF- $\beta 1$ e Activina, dados similares foram obtidos em linhagem de células foliculares de rato FRTL-5 e em linhagem de carcinoma papilífero de tiróide humana TPC (CARNEIRO, 1998; MATSUO, 2001). Sabe-se que a via de Smads é o principal mediador das funções exercidas por TGF $\beta 1$ e activina $A$, entretanto, estudos tem mostrado que TGF-beta possa ativar outras vias, dependente ou independentemente da via Smads. TGF-beta pode ativar componentes da via da MAPK, como ERKs e JNK/SAPKs (MEHRA e WRANA, 2002; DERYNCK e ZHANG, 2003). Esse fator de crescimento ainda pode induzir membros da via Wnt, que também podem estimular c-MYC (CORDRAY e SATTERWHITE, 2005; DANG, O'DONNELL et al., 2006). Estudos futuros serão necessários para elucidar estes achados, uma vez que o proto-oncogene C-MYC não atua somente na progressão do ciclo celular.

Recentemente Schweppe et al, questionaram o uso de linhagens celulares de tiróide utilizadas na identificação de aspectos moleculares envolvidos na carcinogênese dessa glândula, entre elas ARO. Um estudo citogenético revelou uma similaridade muito grande entre ARO e a linhagem HT29, de adenocarcinoma de cólon humano. Sugerindo que ARO e HT29 são provenientes do tumor de cólon humano. Diante desses dados testamos as duas linhagens em questão. Nossa linhagem ARO provém de laboratório do Dr. Fagin (University of Cincinnati College of Medicine, Cincinnati, EUA) e HT29 procedem do ECACC (European Collection of Cell Cultures). Sabe-se que a linhagem celular 
HT29 é indiferenciada quando mantida em meio de cultivo contendo SFB e o cultivo com compostos químicos que contenham dimetilsulfóxido, como butirato de sódio ( $\mathrm{NaBt}$ ), induz modificações em sua morfologia (AUGERON e LABOISSE, 1984). ARO e HT29 são muito semelhantes morfologicamente quando cultivadas em meio de crescimento com SFB (Figura 14 - $2^{\circ}$ dia). Quando submetidas ao tratamento com NaBt a linhagem ARO manteve sua morfologia já a linhagem HT29 teve sua morfologia alterada logo nos primeiros dias de tratamento (Figura $14-6^{\circ} \mathrm{dia}$ ). Após as passagens realizadas ao final do $11^{\circ}$ e $24^{\circ}$ as células retomaram seu formato inicial (sem tratamento) (Figura $15-12^{\circ} \mathrm{dia}$ ), voltando, porém, a apresentar mudanças na morfologia durante o tratamento. HT29 manteve sua morfologia alterada mesmo após o fim do tratamento (Figura 16) e ARO conservou suas características durante todo o experimento, mostrando claramente que se trata de linhagens distintas.

Outra evidência que diferencia ARO de HT29 é a diferença na expressão de TTF-1 e PAX8, fatores específicos da tiróide (Figura 13). Sabendo que TTF-1 e PAX8 são expressos juntos somente em células de origem tireoidiana (FABBRO, DI LORETO et al., 1994) e que a linhagem ARO, mesmo sendo originada de carcinoma anaplásico da tiróide, mantém a expressão de TTF-1 e PAX8 (ZITO, 2008), podemos, dessa forma, afirmar que nossa linhagem ARO possui origem tiroidiana. Tsao e colaboradores (2007) observaram por análise imunohistoquímica que TTF-1 não é expresso em tumores de cólon, confirmando a distinção entre as duas linhagens. Avaliamos ainda a expressão gênica de Arkadia em ARO e HT29. A expressão de Arkadia em ARO é superior a expressão em HT29, sendo cerca de 10 vezes mais expressa na linhagem de carcinoma anaplásico de tiróide do que na linhagem de carcinoma de cólon (Figura 12). Apresentando outra evidência que ARO e HT29 apresentam características distintas. 
Neste trabalho mostramos que a E3 Arkadia é expressa tanto nos tumores tireoidianos, quanto nas linhagens de carcinomas tiroidianos e particularmente mais expressa em linhagem de carcinoma anaplásico. Observamos que a linhagem ARO, originada de carcinoma anaplásico da tiróide, apresenta subclones com expressão gênica diferenciada de Arkadia, de membros da via de sinalização Smads, de genes do ciclo celular modulados por TGF-beta/activina, além de apresentarem grande diferença na formação de tumores in vivo e responderem ao tratamento com peptídeos de TGF-beta1 e activina A. O menor crescimento tumoral e a maior expressão de Arkadia, observados no subclone 2 podem estar relacionados ao fato desta E3 ligase ser capaz de promover a sustentação inibitória promovida pela via de sinalização de TGF- $\beta$ in vivo. 


\section{CONCLUSÃo}

Tumores tireoidianos apresentam expressão de Arkadia. As linhagens ARO, NPA e WRO apresentam expressão gênica de Arkadia, sendo esta expressão maior na linhagem celular de carcinoma anaplásico de tiróide.

Subclones da linhagem celular ARO apresentam diferentes níveis de expressão gênica de Arkadia.

O subclone com maior expressão de Arkadia apresenta maior expressão dos membros da via de sinalização Smads (SMAD2, SMAD3, SMAD4 e SMAD7) e menor crescimento tumoral in vivo, tornando a sustentação da via inibitória de TGF-beta mais eficiente in vivo.

A proliferação e viabilidade não sofrem alterações in vitro. E os subclones de ARO respondem ao tratamento com proteínas recombinantes de TGF-beta e activina. 


\section{REFERENCIAS*}

ARE, C.; SHAHA, A. R. Anaplastic thyroid carcinoma: biology, pathogenesis, prognostic factors, and treatment approaches. Ann. Surg. Oncol., v.13, n.4, Apr., p.453-64, 2006.

ATtISANO, L.; LEE-HOEFLICH, S. T. The Smads. Genome Biol., v.2, n.8, REVIEWS p.3010, 2001.

AUGERON, C.; LABOISSE, C. L. Emergence of permanently differentiated cell clones in a human colonic cancer cell line in culture after treatment with sodium butyrate. Cancer Res., v.44, n.9, Sep., p.3961-9, 1984.

BRADFORD, M. M. A rapid and sensitive method for the quantification of microgram quantities of protein utilizing the principle of protein-dye binding. Anal Biochem., v.72, p.248-54, 1976.

BIENZ, M. The PHD finger, a nuclear protein-interaction domain. Trends Biochem. Sci., v.31, n.1, Jan., p.35-40, 2006.

CARNEIRO C.; ALVARES. C. V.; ZALVIDE J.; VIDAL A.; DOMÍNGUEZ F. TGFbeta1 actions on FRTL-5 cells provide a model for the physiological regulation of thyroid growth. Oncogene, v.16, p.1455-1465, 1998.

CERUTTI, J. M.; EBINA, K. N.; et al. Expression of Smad4 and Smad7 in human thyroid follicular carcinoma cell lines. ]. Endocrinol. Invest., v.26, n.6, Jun., p.516-21, 2003.

CHEN, Y. G. et al. Regulation of cell proliferation, apoptosis, and carcinogenesis by activin. Exp. Biol. Med., Maywood, v.227, n.2, Feb., p.75$87,2002$.

CHOMCZYNSKI, P.; SACCHI, N. Single-step method of RNA isolation by acid guanidinium thiocyanate-phenol-chloroform extraction. Anal. Biochem., v.162, n.1, Apr., p.156-9, 1987.

CIECHANOVER, A.; SCHWARTZ, A. L. The ubiquitin-mediated proteolytic pathway: mechanisms of recognition of the proteolytic substrate and involvement in the degradation of native cellular proteins. Faseb J., v.8, n.2, Feb., p.182-91, 1994.

\section{${ }^{*}$ De acordo com:}

ASSOCIAÇÃO BRASILEIRA DE NORMAS TÉCNICAS. NBR 6023: Informação e documentação: referências: elaboração. Rio de Janeiro, 2002. 
CONAWAY, R. C. et al. Emerging roles of ubiquitin in transcription regulation. Science, v.296, n.5571, May 17, p.1254-8, 2002.

CORDRAY, P.; SATTERWHITE, D. J. TGF-beta induces novel Lef-1 splice variants through a Smad-independent signaling pathway. Dev. Dyn., v.232, n.4, Apr., p.969-78, 2005.

DANG, C. V. et al. The c-Myc target gene network. Semin. Cancer Biol., v.16, n.4, Aug., p.253-64, 2006.

DERYNCK, R.; ZHANG, Y. E. Smad-dependent and Smad-independent pathways in TGF-beta family signalling. Nature, v.425, n.6958, Oct. 9, p.57784, 2003.

EBISAWA, T. et al. Smurf1 interacts with transforming growth factor-beta type I receptor through Smad7 and induces receptor degradation. J. Biol. Chem., v.276, n.16, Apr. 20, p.12477-80, 2001.

EPISKOPOU, V. et al. Induction of the mammalian node requires Arkadia function in the extraembryonic lineages. Nature, v.410, n.6830, Apr. 12, p.825-30, 2001.

EPPERT, K.; SCHERER. S. W.; OZCELIK, H.; PIRONE, R.; HOODLESS, P.; KIM, H.; TSUI, L. C.; BAPAT, B.; GALLINGER, S.; ANDRULIS, I. L.; THOMSEN, G. H.; WRANA, J. L.; ATTISANO, L. MADR2 maps to $18 \mathrm{q} 21$ and encodes a TGFbeta-regulated MAD-related protein that is functionally mutated in colorectal carcinoma. Cell, v.86, p.9, 1996.

FABBRO, D.; C. et al. Expression of thyroid-specific transcription factors TTF-1 and PAX-8 in human thyroid neoplasms. Cancer Res., v.54, n.17, Sep. 1, p.4744-9, 1994.

FAGIN, J. A. et al. High prevalence of mutations of the p53 gene in poorly differentiated human thyroid carcinomas. J. Clin. Invest., v.91, n.1, Jan., p.179-84, 1993.

FANG, G. Checkpoint protein BubR1 acts synergistically with Mad2 to inhibit anaphase-promoting complex. Mol. Biol. Cell, v.13, n.3, Mar., p.755-66, 2002.

FRANZEN, A. et al. Expression of transforming growth factor-beta1, activin A, and their receptors in thyroid follicle cells: negative regulation of thyrocyte growth and function. Endocrinology, v.140, n.9, Sep., p.4300-10, 1999.

GIMENES, F. Y.; MATSUO, S. E.; EBINA, K. N.; KIMURA, E. T. Expressão proteica dos receptores de TGF-beta, receptor tipo I (TBRI) e tipo II (TBRII), em tumores benignos e malignos da tiróide. In: CONGRESSO PAULISTA DE ENDOCRINOLOGIA E METABOlOGIA, 6., 2005, São Paulo. Anais... São Paulo: Centro de Convenções Frei Caneca - COPEM, 2005. p.S72. 
GLASGOW, E.; MISHRA, L. Transforming growth factor-beta signaling and ubiquitinators in cancer. Endocr. Relat. Cancer, v.15, n.1, Mar., p.59-72. 2008.

GOLD, L. I. The role for transforming growth factor-beta (TGF-beta) in human cancer. Crit. Rev. Oncog., v.10, n.4, p.303-60, 1999.

GUIMARAES, G. S. et al. Identification of candidates for tumor-specific alternative splicing in the thyroid. Gen. Chromos. Can., v.45, n.6, Jun., p.540$53,2006$.

HAHN, S. A.; SCHUTTE, M.; HOQUE, A. T.; MOSKALUK, C. A.; DA COSTA, L. T.; ROZENBLUM, E.; WEINSTEIN, C. L.; FISCHER, A.; YEO, C. J.; HRUBAN, R. H.; KERN, S. E. DPC4, a candidate tumor suppressor gene at human chromosome 18q21.1. Science, v.271, p.3, 1996.

HARPER, J. W. Protein destruction: adapting roles for Cks proteins. Curr. Biol., v.11, n.11, Jun. 5, p. R431-5, 2001.

HARTMANN-PETERSEN, R. et al. Transferring substrates to the $26 \mathrm{~S}$ proteasome. Trends Biochem. Sci., v.28, n.1, Jan., p.26-31, 2003.

HATAKEYAMA, S.; NAKAYAMA, K. I. U-box proteins as a new family of ubiquitin ligases. Biochem. Biophys. Res. Commun., v.302, n.4, Mar. 21, p.635-45, 2003.

HAYASHI, $\mathrm{H}$. et al. The MAD-related protein Smad7 associates with the TGFbeta receptor and functions as an antagonist of TGFbeta signaling. Cell, v.89, n.7, Jun. 27, p.1165-73, 1997.

HERSHKO, A.; CIECHANOVER, A. The ubiquitin system for protein degradation. Annu. Rev. Biochem., v.61, p.761-807, 1992.

HERSHO, A.; CIECHANOVER, A. The ubiquitin system. Annu. Rev. Biochem., v.67, p.425-79, 1998.

ISHIMI, Y. A. DNA helicase activity is associated with an MCM4, -6 , and -7 protein complex. J. Biol. Chem., v.272, n.39, Sep. 26, p.24508-13, 1997.

IZZI, L.; ATTISANO, L. Regulation of the TGFbeta signalling pathway by ubiquitin-mediated degradation. Oncogene, v.23, n.11, Mar. 15, p.2071-8, 2004.

KAVSAK, P. et al. Smad7 binds to Smurf2 to form an E3 ubiquitin ligase that targets the TGF beta receptor for degradation. Mol. Cell, v.6, n.6, Dec., p.1365-75, 2000. 
KIMURA, E. T. et al. Expression of transforming growth factor beta1, beta2, and beta 3 in multinodular goiters and differentiated thyroid carcinomas: a comparative study. Thyroid, v.9, n.2, Feb., p.119-25, 1999.

KIMURA, E. T. et al. TGFbeta, activin and SMAD signalling in thyroid cancer. Arq. Bras. Endocrinol. Metabol., v.51, n.5, Jul., p.683-9, 2007.

KOINUMA, D. et al. Arkadia amplifies TGF-beta superfamily signalling through degradation of Smad7. Embo. J., v.22, n.24, Dec. 15, p.6458-70, 2003.

LANEY, J. D.; HOCHSTRASSER, M. Substrate targeting in the ubiquitin system. Cell, v.97, n.4, May 14, p.427-30, 1999.

LAZZERESCHI, D. N. F.; TURCO, A.; OTTINI, L.; D'AMICO, C.; MARIANICOSTANTINI, R.; GULINO, A.; COPPA, A. A complex pattern of mutations and abnormal splicing of Smad4 is present in thyroid tumours. Oncogene, 2005.

LEBRUN, J. J. et al. Roles of pathway-specific and inhibitory Smads in activin receptor signaling. Mol. Endocrinol., v.13, n.1, Jan., p.15-23, 1999.

LIU, X. et al. Phosphorylation regulation of the interaction between Smad7 and activin type I receptor. FEBS. Lett., v.519, n.1-3, May 22, p.93-8, 2002.

LORICK, K. L. et al. RING fingers mediate ubiquitin-conjugating enzyme (E2)dependent ubiquitination. Proc. Natl. Acad. Sci. U. S. A., v.96, n.20, Sep. 28, p.11364-9, 1999.

LOVERING, R. et al. Identification and preliminary characterization of a protein motif related to the zinc finger. Proc. Natl. Acad. Sci. U. S. A., v.90, n.6, Mar. 15, p.2112-6, 1993.

MARKOWITZ, S. et al. Inactivation of the type II TGF-beta receptor in colon cancer cells with microsatellite instability. Science, v.268, n.5215, Jun. 2, p.1336-8, 1995.

MASSAGUE, J. TGF-beta signal transduction. Annu. Rev. Biochem., v.67, p.753-91, 1998.

MASSAGUE, J. et al. TGFbeta signaling in growth control, cancer, and heritable disorders. Cell, v.103, n.2, Oct. 13, p.295-309, 2000.

MASSAGUE, J.; WOTTON, D. Transcriptional control by the TGF-beta/Smad signaling system. Embo J., v.19, n.8, Apr. 17, p.1745-54, 2000.

MATSUO, S. E. Expressão de Activina betaA e Activina betaB em Bócios de Ratos e em Tumores de Tiróide Humana. $54 \mathrm{f}$. Departamento de Biologia Celular e do Desenvlvimento - Instituto de Ciências Biomédicas, Universidade de São Paulo, São Paulo, 2001. 
MATSUO, S.E. Efeito do Bloqueio do Gene de Activina e do Gene de TGF-beta na Via de Sinalização de Smads e na Proliferação de Células Foliculares da Tiróide. 71 f. Departamento de Biologia Celular e do Desenvolvimento, Universidade de São Paulo, São Paulo, 2005.

MATSUO, S. E.; FRIGUGLIETTI, C. U. M.; KULCSAR, M. A. V.; KIMURA, E. T. Integridade da sinalização de TGF-beta/Smads em tumors de tiróide humana. In: ENCONTRO BRASILEIRO DE ENDOCRINOLOGIA, 11., 2004, Vitória - ES Anais... Arq.Bras.Endo.Metab., 2004. p.S291

MATSUO, S. E. et al. Activin betaB expression in rat experimental goiter and human thyroid tumors. Thyroid, v.13, n.3, Mar., p.239-47, 2003.

MATSUO, S. E. et al. Transforming growth factor-beta1 and activin A generate antiproliferative signaling in thyroid cancer cells. J. Endocrinol., v.190, n.1, Jul., p.141-50, 2006.

MEHRA, A.; WRANA, J. L. TGF-beta and the Smad signal transduction pathway. Biochem. Cell. Biol., v.80, n.5, p.605-22, 2002.

MINCIONE, G. et al. Loss of thyrotropin regulation and transforming growth factor beta-induced growth arrest in erbB-2 overexpressing rat thyroid cells. Cancer Res., v.53, n.22, Nov. 15, p.5548-53. 1993.

MITSUTAKE, N. et al. Characterization of side population in thyroid cancer cell lines: cancer stem-like cells are enriched partly but not exclusively. Endocrinology, v.148, n.4, Apr., p.1797-803, 2007.

MIYAZAWA, K. et al. Two major Smad pathways in TGF-beta superfamily signalling. Genes Cells, v.7, n.12, Dec., p.1191-204, 2002.

MIYAZONO, K. et al. Regulation of TGF-beta signaling and its roles in progression of tumors. Cancer Sci., v.94, n.3, Mar., p.230-4, 2003.

MOSMANN, T. Rapid colorimetric assay for cellular growth and survival: application to proliferation and cytotoxicity assays. J. Immunol. Methods, v.65, n.1-2, Dec. 16, p.55-63, 1983.

NIEDERLANDER, C. et al. Arkadia enhances nodal-related signalling to induce mesendoderm. Nature, v.410, n.6830, Apr. 12, p.830-4, 2001.

NIKIFOROVA, M. N. et al. BRAF mutations in thyroid tumors are restricted to papillary carcinomas and anaplastic or poorly differentiated carcinomas arising from papillary carcinomas. ]. Clin. Endocrinol. Metab., v.88, n.11, Nov., p.5399-404,2003

PANGAS, S. A.; WOODRUFF, T. K. Activin signal transduction pathways. Trends Endocrinol. Metab., v.11, n.8, Oct., p.309-14, 2000. 
PARDAL, R. et al. Applying the principles of stem-cell biology to cancer. Nat. Rev. Cancer, v.3, n.12, Dec., p.895-902, 2003.

PFAFFL, M. W. A new mathematical model for relative quantification in realtime RT-PCR. Nucleic Acids Res., v.29, n.9, May 1, p.e45, 2001.

POWELL, S. M.; HARPER, J. C.; HAMILTON, S. R.; ROBINSON, C. R.; CUMMINGS, O. W. Inactivation of Smad4 in gastric carcinomas. Cancer Res., v.57, p.3, 1997.

PRAY, T. R. et al. Cell cycle regulatory E3 ubiquitin ligases as anticancer targets. Drug Resist. Updat., v.5, n.6, Dec., p.249-58, 2002.

REIS, E. M. et al. Large-scale transcriptome analyses reveal new genetic marker candidates of head, neck, and thyroid cancer. Cancer Res., v.65, n.5, Mar. 1, p.1693-9, 2005.

RICARTE-FILHO. J. C. M.; KIMURA, E. T. Expressão gênica e imunohistoquímica das E3 ubiquitina-ligases Smurf1 e Smurf2 em carcinomas tiroidianos. In: CONGRESSO PAULISTA DE ENDOCRINOLOGIA E METABOlogiA, 6., 2005, São Paulo. Anais... São Paulo: Centro de Convenções Frei Caneca - COPEM, 2005. p.S77.

ROBERTS, A. B.; SPORN, M. B. Peptide Growth Factors and their Receptors I. New York: Springer-Verlag, 1991. p.418-472. (The Transforming Growth Factor-betas).

SCHEFFNER, M. et al. The HPV-16 E6 and E6-AP complex functions as a ubiquitin-protein ligase in the ubiquitination of p53. Cell, v.75, n.3, Nov. 5, p.495-505, 1993.

SCHEFFNER, M. et al. Protein ubiquitination involving an E1-E2-E3 enzyme ubiquitin thioester cascade. Nature, v.373, n.6509, Jan. 5, p.81-3, 1995.

SPIRES, J. R. et al. Anaplastic thyroid carcinoma. Association with differentiated thyroid cancer. Arch. Otolaryngol. Head Neck. Surg., v.114, n.1, Jan., p.40-4, 1988.

TAKAGI, Y.; KOHMURA, H.; FUTAMURA, M.; KIDA, H.; TANEMURA, H.; SHIMOKAWA, K.; SAJI, S. Somatic alterations of the DPC4 gene in human colorectal cancers in vivo. Gastroenterology, v.111, p.4, 1996.

TAKANO, T. Fetal cell carcinogenesis of the thyroid: theory and practice. Semin. Cancer Biol., v.17, n.3, Jun., p.233-40, 2007.

TAKANO, T.; AMINO, N. Fetal cell carcinogenesis: a new hypothesis for better understanding of thyroid carcinoma. Thyroid, v.15, n.5, May, p.432-8, 2005. 
TAKANO, T. et al. Expression of oncofetal fibronectin mRNA in thyroid anaplastic carcinoma. Jpn. J. Clin. Oncol., v.37, n.9, Sep., p.647-51, 2007.

WANG, X. et al. Significance of MAD2 expression to mitotic checkpoint control in ovarian cancer cells. Cancer Res., v.62, n.6, Mar. 15, p.1662-8, 2002.

WICHA, M. et al. Cancer Stem cells: An Old Idea-A Paradigm Shift. Cancer Res., v.66, Feb., 15, p.1883 - 1890, 2006.

WOLFRAIM, L. A.; FERNANDEZ, T. M.; MAMURA, M.; FULLER, W. L.; KUMAR, R.; COLE, D. E.; BYFIELD, S.; FELICI, A.; FLANDERS, K. C.; WALZ, T. M.; ROBERTS, A. B.; APLAN, P. D.; BALIS, F. M.; LETTERIO, J. J. Loss of Smad3 in acute T-cell lymphoblastic leukemia. N. Engl. J. Med., v.351, p.7, 2004.

YAKICIER, M. C.; IRMAK, M. B.; ROMANO, A.; KEW, M.; OZTURK, M. Smad2 and Smad4 gene mutations in hepatocellular carcinoma. Oncogene, v.18, p.5, 1999.

YANAGISAWA, K.; UCHIDA, K.; NAGATAKE, M.; MASUDA, A.; SUGIYAMA, M.; SAITO, T.; YAMAKI, K.; TAKAHASHI, T.; OSADA, H. Heterogeneities in the biological and biochemical functions of Smad2 and Smad4 mutants naturally occurring in human lung cancers. Oncogene, v.19, p.6, 2000.

Yin, A. H.; Miraglia, S.; Zanjani, E. D. ; Almeida-Porada, G.; Ogawa, M.; Leary, A. G.; Olweus, J.; Kearney, J.; Buck, D. W. AC133, a novel marker for human hematopoietic stem and progenitor cells. Blood, v.90, n.12, Dec. 15, p.500212, 1997.

ZHU, Y.; RICHARDSON, J. A.; PARADA, L. F.; GRAFF, J. M. Smad3 mutant mice develop metastatic colorectal cancer. Cell, v.94, p.11, 1998.

ZITO, G.; RICHIUSA, P.; BOMMARITO, A.; CARISSIMI, E.; RUSSO, L.; COPPOLA, A.; ZERILLI, M.; RODOLICO, V.; CRISCIMANNA, A.; AMATO, M.; PIZZOLANTI, G.; GALLUZZO, A.; GIORDANO, C. In Vitro Identification and Characterization of $\mathrm{CD} 133^{\text {pos }}$ Cancer Stem-Like Cells in Anaplastic Thyroid Carcinoma Cell Lines. PLoS ONE, v.3, n.10, Oct., p.10, 2008. 